University of Nebraska - Lincoln

DigitalCommons@University of Nebraska - Lincoln

Congreso internacional sobre iconografía

precolombina, Barcelona 2019. Actas.

8-20-2020

\title{
Ancestros, nahuales y hombres (I). Las host figurines \\ teotihuacanas: hacia una definición, caracterización tipológica y acercamiento iconográfico
}

Annabel Villalonga Gordaliza

Follow this and additional works at: https://digitalcommons.unl.edu/actas2019

Part of the American Material Culture Commons, Indigenous Studies Commons, Museum Studies Commons, Other History of Art, Architecture, and Archaeology Commons, and the Other Languages, Societies, and Cultures Commons

This Article is brought to you for free and open access by the Zea E-Books at DigitalCommons@University of Nebraska - Lincoln. It has been accepted for inclusion in Congreso internacional sobre iconografía precolombina, Barcelona 2019. Actas. by an authorized administrator of DigitalCommons@University of Nebraska - Lincoln. 


\title{
Ancestros, nahuales y hombres (I). Las host figurines teotihuacanas: hacia una definición, caracterización tipológica y acercamiento iconográfico
}

\author{
Annabel Villalonga Gordaliza \\ Universitat Autònoma de Barcelona, Departamento de Arte \\ Annabel.Villalonga@uab.cat
}

\begin{abstract}
Resumen:
En 1934 George Vaillant adquirió en Ahuizotla una inédita escultura de barro cuyo cuerpo contenía pequeñas figurillas hechas a molde. No sería hasta 1976 cuando por primera vez Warren Barbour, designó como host figurines o figurillas tipo huésped, a un conjunto de figurillas huecas de cerámica, en posición sedente, que contenían en su interior a otras figurillas hechas a molde que procedían de Teotihuacán. Aunque generalmente habían aparecido en entierros y depósitos de ofrendas en la antigua urbe, también existen ejemplares que proceden de lugares más distantes de Mesoamérica. El propósito de este estudio preliminar consiste en revisar las host figurines teotihuacanas, especialmente aquellas que proceden de contexto arqueológico. En esta propuesta inicial se tratan de definir los tipos, establecer sus variantes y analizar iconográficamente la presencia de algunos elementos simbólicos detectados.
\end{abstract}

Parabras clave: figurillas huésped, Teotihuacan

\section{Abstract:}

In 1934 George Vaillant acquired in Ahuizotla a unique clay sculpture whose body contained small mold-made figurines. For the first time in 1976, Warren Barbour named "host figurines" a cluster of large hollow ceramic figurines, in a seated position, containing other mold clay figurines that had been found in Teotihuacán. Although they have generally appeared in burials and caches in the ancient city, there are also samples that come from other parts of Mesoamerica. The purpose of this study is to review the host figurines, above all those appeared in archaeological context. The purpose of this preliminary study is to review the host Teotihuacan figurines, especially those that come from an archaeological context. In this initial proposal we try to define the types, establish their variants and approach their iconography.

Keywords: host figurines, Teotihuacan

(ㅇ) (ㅇ)

Entre 1928-1936 George Clapp Vaillant, con el apoyo del American Museum of Natural History (AMNH) emprendió nueve temporadas de excavaciones en México. En $1934^{1}$ mientras trabajaba en Santiago Ahuizotla,

1. Existe discrepancia en los años, ya que según los datos facilitados por el museo se indica que en 1934 G.C. Vaillant excavó en Santiago Ahuizotla "El Corral" y en 1936 en Los Melones, Texcoco. Sin embargo en el manuscrito se hace referencia en el encabezado a "Museum Expedition 1936-10. Vicinity of El Corral". Este dato coincide con los datos de adquisición de la pieza por parte del museo. También se menciona que durante el mes de Octubre de 1934 Vaillant "visited these sites and either bought objects or made small surface collections: Huexotla; Coatlihuchan [. . .]".Quisiera señalar en este sentido que la publicación en la que W. Barbour (Berrin \& Pasztory, 1993:213, cat.63) refería que esta pieza fue adquirida en 1933 en Ahuexotla se trata posiblemente de un error. No solo del año sino también del lugar, confundiendo al parecer los dos topónimos Santiago Ahuizotla (Amantla) en Azcapotzalco y Huexotla (Texcoco).

Publicado en Congreso internacional sobre iconografía precolombina, Barcelona 2019. Actas, Victòria Solanilla Demestre, editora (Lincoln, Nebraska: Zea Books, 2020). https://doi.org/10.32873/unl.dc.zea.1244 
Azcapotzalco, adquirió en las inmediaciones de este lugar, una escultura cerámica que definió como "complete figurines (nearly) hollow with small figurines inside"2 (figura 1,4b). Al parecer éste fue el primer ejemplar conocido de un conjunto de esculturas huecas cerámicas que hoy son objeto de este artículo. En 1976, Warren Barbour designó como host figurines o figurillas tipo hués$\operatorname{ped}^{3}$ a un conjunto de grandes figurillas huecas de cerámica, en posición sedente, que contenían en su interior a otras figurillas hechas a molde. Los primeros ejemplares proceden de las afueras de Teotihuacán y otros lugares de Mesoamérica donde la metrópolis del Altiplano había mantenido redes comerciales o irradiado su influencia. No fue hasta 1981 que se hallaron en la antigua urbe (Barbour 1986:55).

\section{Algunas consideraciones preliminares}

Cuando revisamos la literatura existente que versa sobre este asunto, realmente es muy dispersa ${ }^{4}$, así que una parte del objetivo de este artículo consiste en sintetizar lo escrito. A partir de los ejemplares recopilados hasta el momento se propone una definición y caracterización inicial de los tipos y sus variantes. También se destaca y se analiza la presencia de unos elementos iconográficos recurrentes. En una segunda fase de investigación (artículo en preparación) procedemos a revisar y a discutir los contextos y las interpretaciones dadas, así como a sugerir nuevas perspectivas de estudio.

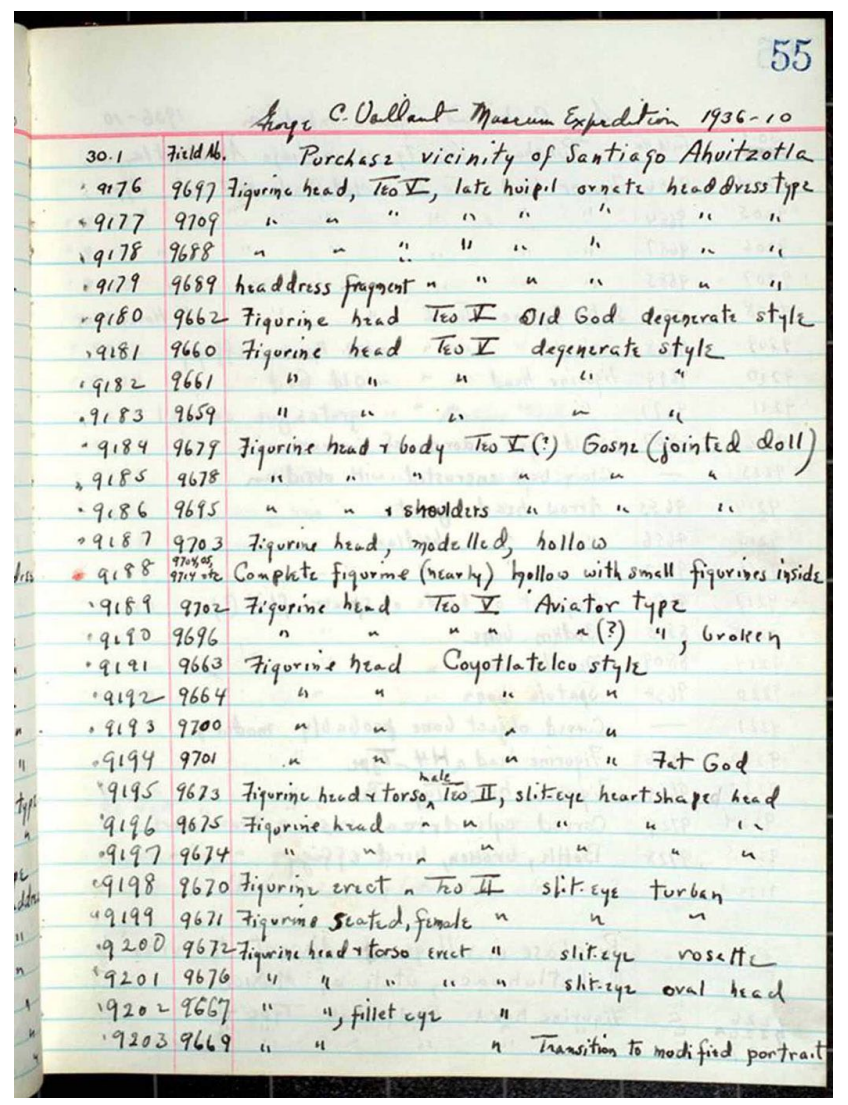

Figura 1: Catálogo de manuscritos digitalizados del AMNH. George C. Vaillant Museum Expedition 1936-10. Pág. 55. Referencia Catalog No: 30.1/9188.

2. La adquisición de objetos arqueológicos venía siendo una práctica habitual en la época. El manuscrito se precede de un encabezado "Purchase vicinity of Santiago Ahuizotla" al que sigue un listado de los materiales comprados.

3. Incluye la mención en la tesis, inicialmente en los comentarios a las tipologías de figurillas tratando a las "Puppets" o muñecas articuladas al advertir la existencia de algunos ejemplares huecos en Tlaxcala que además contenían pequeñas figuras en el pecho y estómago y advierte "This phenomenon does occur in large hollow Teotihuacán figurines which are not puppets" (plates 91 and 87). (Barbour 1976:17). Merece la pena mencionar que W. Barbour ha abordado el tema de las host figurines en conferencias y ponencias, aunque nunca se ha publicado nada al respecto. Consta una conferencia "Host Figurines and the Social Order of Teotihuacan: Soldiers, Traders, Diviners and Peasants" en el Sharp Auditorium del Museo de Denver dentro de un simposio, "The Art of Teotihuacan \& its sphere of influence" (7-8 Noviembre de 2009). Matthew Robb (comunicación personal 06/05/2019) me indicó que W. Barbour no asistió al encuentro de Denver. En 1986 Barbour pronunció en el marco del 51st Annual Meetings of he Society for American Archaeology, New Orleans, April, en el Simposio 2 "Craft production, idea systems, and Teotihuacan society" una ponencia que llevó por título "Shadow and substance: the iconography of Host Figurines associated with ancient Teotihuacan“ (An analysis of Teotihuacan-type host figurines) un manuscrito que tampoco nunca llegó a publicarse ni ha sido posible localizar. Solo K. Goldsmith y K. Berrin (comunicación personal) afirman haber leído el documento, pero ambas no recuerdan dónde. En consecuencia, los escasos datos presentados aquí en relación al autor proceden de comunicaciones de investigadores que asistieron a sus ponencias y/o leyeron sus manuscritos y me han trasmitido el resumen de las mismas.

4. A pesar de que las aportaciones de Barbour debieron ser interesantes, nunca fueron publicadas. La única publicación que intenta sintetizar este tema vino de la mano de E. Pasztory (1997:171-176) quién dedicó algunas páginas a revisar los ejemplares y la literatura existente al respecto. 
Debemos considerar que de los diez ejemplares recopilados para este estudio solamente dos proceden de excavaciones controladas de los que tenemos datos confiables para replantear cronologías, contextos y funciones. No obstante, prácticamente un $60 \%$ de la muestra analizada procede de museos y se desconoce su contexto primario, sin embargo se ha considerado igualmente, puesto que parte del objetivo del estudio trata también de generar un corpus al respecto.

Finalmente considerar que estamos en proceso de recabar más información procedente de museos europeos que a la fecha de este artículo, aun no habían enviado la información solicitada. Esperemos que en un futuro podamos contar con otros ejemplares que incrementen la muestra.

\section{Los ejemplares del análisis}

Se han recabado un total de diez ejemplares que ha centrado el objeto de análisis de este artículo. En primer lugar cabe mencionar que si bien contamos con otros ejemplares ${ }^{5}$, se han excluido de este análisis, ya sea por carecer de datos suficientes acerca de su procedencia y/o porque sus dimensiones son menores a $8 \mathrm{cms}$. y entonces podrían constituir la categoría de figurillas.

\section{Definición y caracterización de los tipos}

Las host figurines responden a un patrón morfológico muy variable. Las definimos como figuras huecas de cerámica que se dividen en dos partes: la figura exterior que se designa como anfitriona y las diminutas figurillas hechas a molde ${ }^{6} \mathrm{y}$ planas de su parte interior, que son las que se conocen como huéspedes. En primer lugar cabe apreciar que el modo en que éstas anfitrionas se expresan es muy distinto, aunque uno de los rasgos que comparten es que están sentadas, aunque en diversas posiciones y que todas están desnudas y son asexuadas. Por otro lado la manera en que estas figuras se abren responde a dos tipologías que, en el conjunto estudiado, suponen el $50 \%$ de los ejemplares para cada tipo. Las figuras huésped o bien presentan una oquedad trapezoidal en el pecho o caja torácica, como los ejemplares HF1 (Figura 2a), HF4 (Figura 2b), HF7 (Figura 3b), HF6 (Figura 3a) y HF10 (Figura 3c) o bien el cuerpo se segmenta en dos mitades, la frontal y la posterior, es el caso de la HF2 (Figura 4a), HF3 (Figura 4b), HF5 (Figura 4c), HF8 (Figura 5a) y HF9 (Figura 5b). Para los cinco primeros casos que presentan nicho trapezoidal vaciado en el cuerpo de la anfitriona, solo encontramos un ejemplar, la figura HF7 (Figura 3b), que reside en dicho interior y una más en la parte posterior de la tapadera, en todos de los casos en que ésta se ha conservado. La otra tipología que segmenta el cuerpo en dos mitades se caracteriza por subdividirse a su vez en dos tipos: cuando las dos mitades del cuerpo son completamente vaciadas, desde la cabeza hasta las piernas, ejemplificado con las HF2 (Figura 4a), HF5 (Figura 4c) y HF9 (Figura 5b) y los dos casos restantes HF3 (Figura 4b) y HF8 (Figura 5a) que sólo han vaciado el tronco y las extremidades, la cabeza por lo tanto, no se ha vaciado. No obstante, en ambos subtipos destaca una distribución espacial interior esmerada: una figura ocupa la cabeza, otra se sitúa en el eje de la columna vertebral y otras figuras ocupan las extremidades.

\section{Rasgos comunes}

Como ya ha sido apuntado por varios autores (Barbour, 1993:210; Pasztory 1997:171), todas las host figurines se muestran asexuadas, es decir, sin representación explícita del sexo ni tampoco aparecen indicadores físicos de masculinidad o feminidad. Respecto a su asexualidad, como también sucede en la litoescultura antropomorfa teotihuacana (Villalonga 2014: 433-451), varios autores apuntaron a la posibilidad que las figuras llevaran la indumentaria hecha con materiales perecederos como el papel o tejido (Noguera, 1975:136; Uriarte 1994:95), que no se habría conservado y que posiblemente concedería la indumentaria que definiera el género. Esta opción es plausible y explicaría su género, en el supuesto que éste se quisiera expresar. Sin embargo

5. En el Natural History Museum de Los Angeles se encuentra una figura del tipo host (inventario n. F.A. 995.93-8 A, B) que fue donada por H. Von Winning y su esposa. Aunque Berrin \& Pasztory (1993:213, cat. 64) indicaron que la procedencia era desconocida, los datos facilitados por el museo indican que procede de Santiago Ahuizotla. También el MNAM expone en sala una figurilla de 7cms (no inventario 09.0-01322) y no consta en bodega ni en bóveda otra de este tipo (Edgar Ariel Rosales de la Rosa, curador de la sala teotihuacana, comunicación personal). También en el Museo de Sitio de Teotihuacán se encuentra una muy similar a la consignada en este artículo como HF5 (Figura 4c) pero no ha sido posible a fecha entrega del artículo obtener las dimensiones.

6. El ejemplar HF7 (Figura 3b) es anómalo en este sentido también ya que presenta la figura huésped del abdomen elaborada a mano. 


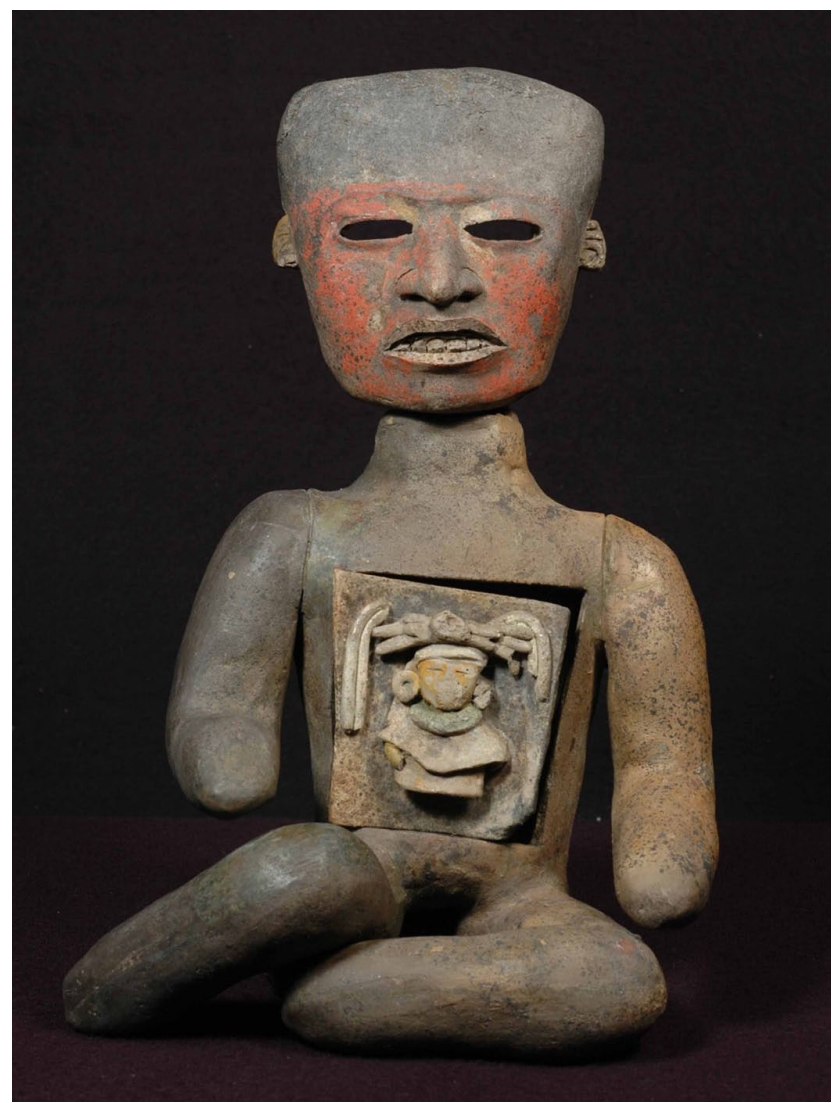

Figura 2a: HF1. Museo de Sitio de Teotihuacan. INAH 10411079. $18.5 \times 20 \times 12 \mathrm{~cm}$. Imagen cedida por el fotógrafo Miguel Morales.

cabe asimismo considerar la posibilidad que fueran concebidas ya como asexuadas ab initio y que, en consecuencia, esa voluntaria asexualidad formara parte de un discurso interpretativo-simbólico.

\section{Anfitrionas: Posturas}

Existen dos posiciones básicas detectadas en el grupo de host figurines analizado ${ }^{7}$.

HF1 (Figura 2a) excavada en Tlajinga33 y HF7 (Figura 3b) del Musée du Quai Branly tienen una posición sedente con la piernas dobladas hacia un mismo lado (derecho) y con los brazos que descansan cerca de las rodillas, aunque apenas sin tocarlas. Entre estos dos ejemplares nótese que en la HF1 las extremidades inferiores no son visibles, sino que acaban en forma redondeada. Otra postura identificada es sentada con las

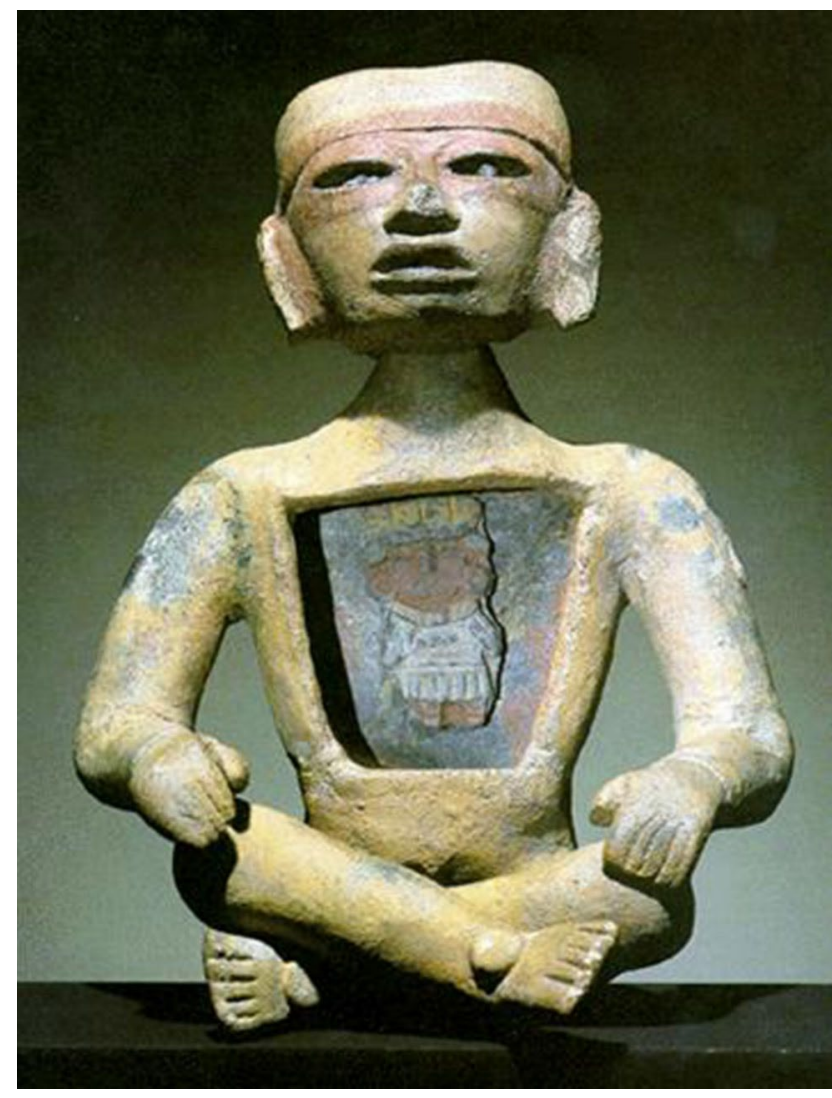

Figura 2b: HF4. Museo de Antropología de México, D.F. INAH 10-223779; MNA 09.0-03585. 13.6x10,5 cm. Tomado de K. Berrin \& E. Pasztory (1993: cat 62, p.212).

piernas cruzadas con las extremidades inferiores visibles. A esta variante corresponden seis ejemplares: HF2 (Figura 4a) del Museo Anahuacalli, HF4 (Figura 2b) del Museo Nacional de Antropología de México, HF5 (Figura 4c) del Museo de Sitio de la ZAT, HF8 (Figura 5a) del Metropolitan Museum of Art, HF9 (Figura 5b) del Museo Regional de Yucatán "Palacio Cantón” y HF10 (Figura 3c, 6) del Ethnologisches Museum de Berlín o tal vez siete, si consideramos la HF3 (Figura 4b) del AMNH . Este último ejemplar es problemático porque fue sometido a una restauración errónea, según menciona Warren Barbour (1993:213) puesto que fue hallado sin la parte inferior. Inicialmente les dió la impresión de que estaba arrodillado, por eso remodelaron la parte baja de la escultura. Si partimos de la sugerencia que Barbour sostiene, la figura en realidad mostraría las piernas cruzadas. Añadiré al respecto que para W. Barbour (1993) las

7. Uno de los ejemplares que posee el Sant Louis Art Museum (HF6) (Figura 3a) no puede considerarse a este análisis puesto que solo es un busto fragmentado. 


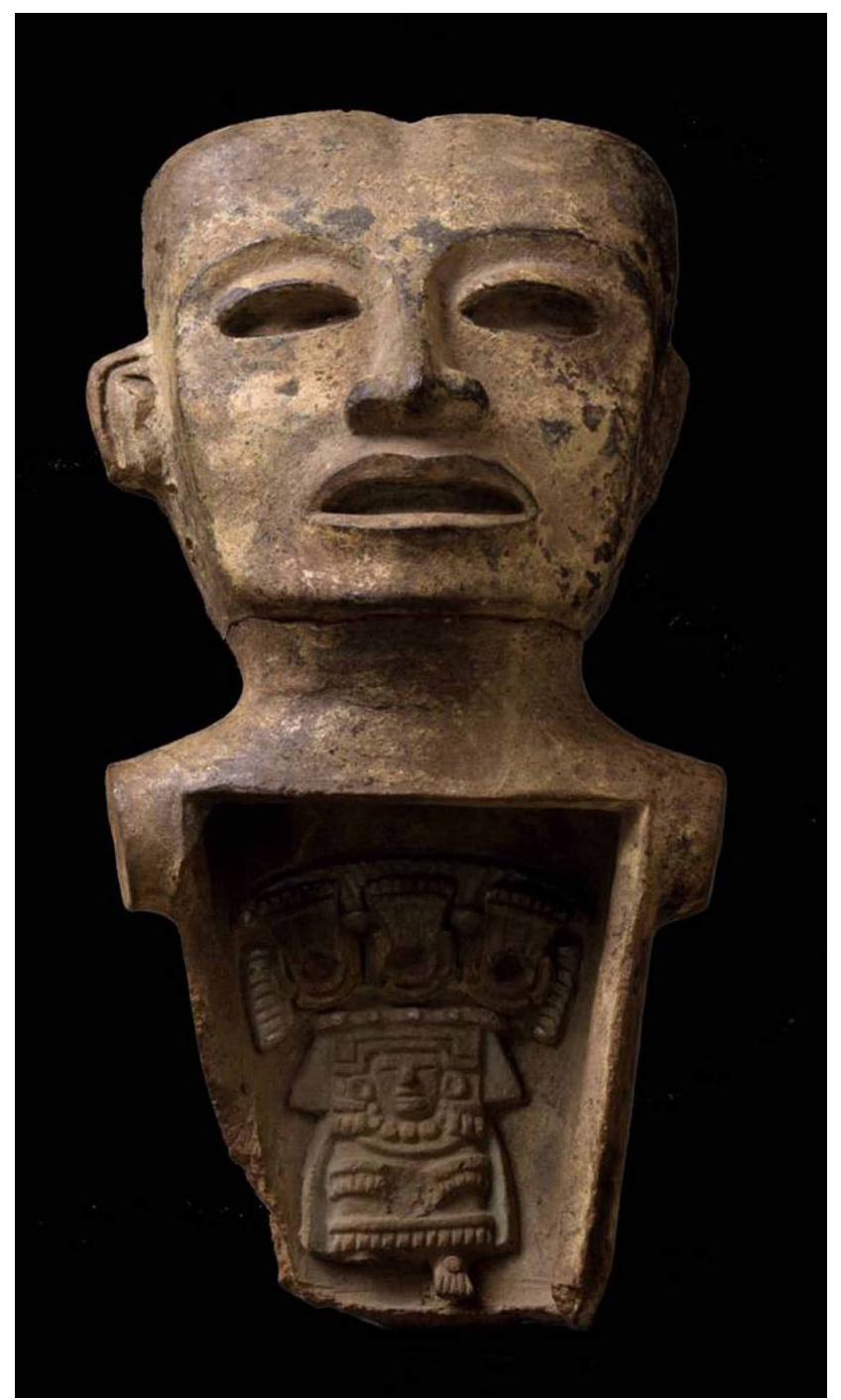

Figura 3a: HF6. Saint Louis Art Museum. 230:1978. 20.2 $\times 10.1 \times 6.6 \mathrm{~cm}$. Retocada a partir de la imagen disponible en la web https://www.slam.org/collection/objects/8863/

posturas diferenciales, piernas cruzadas o hacia un lado son los indicadores del género, masculino y femenino respectivamente.

El tipo mayormente representado es aquel que muestra las piernas cruzadas y constituye un $78 \%$, frente al $22 \%$ que representa la posición sedente con las piernas dobladas hacia un mismo lado.

\section{Anfitrionas: atuendos y rasgos corporales}

En este apartado es donde existe mayor diversidad. En primer lugar mencionamos los dos ejemplares más austeros de todos. Se trata del HF5 ( Figura 4c) del Museo

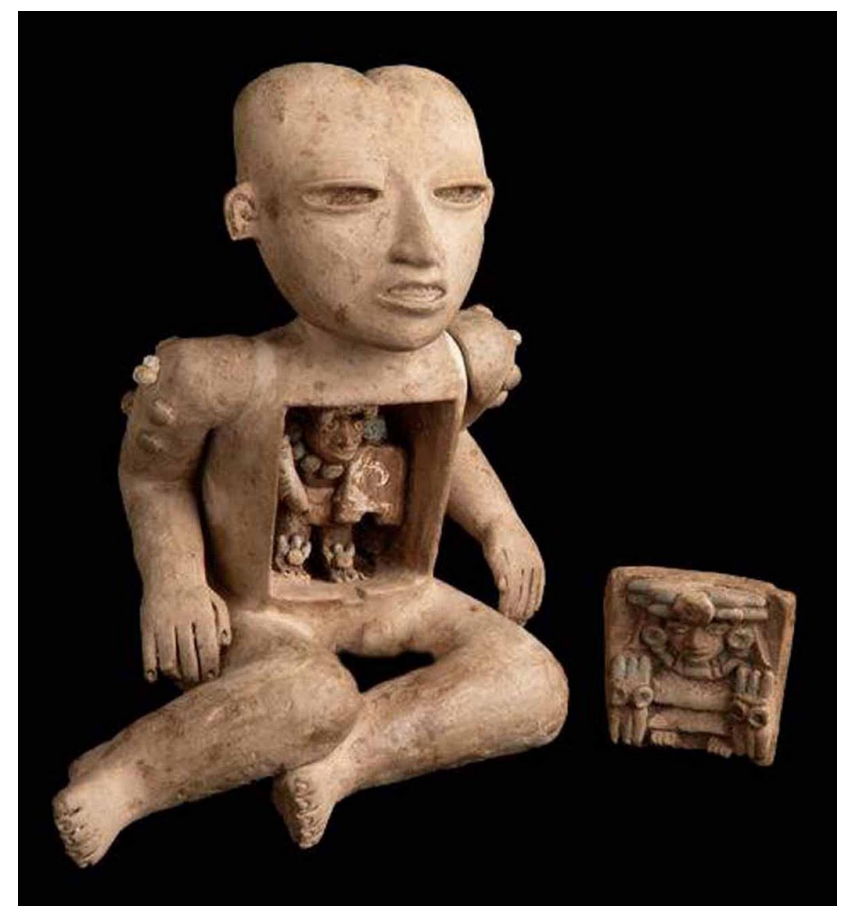

Figura 3b: HF7. Musée du quai Branly. 70.2001.14.1.12. $12 \times 13 \times 8 \mathrm{~cm}$. Retocada a partir de las imágenes disponibles en la web http://www.quaibranly.fr/ es/explora-colecciones/base/Work/action/show/ notice/360038-figurine-gigogne/

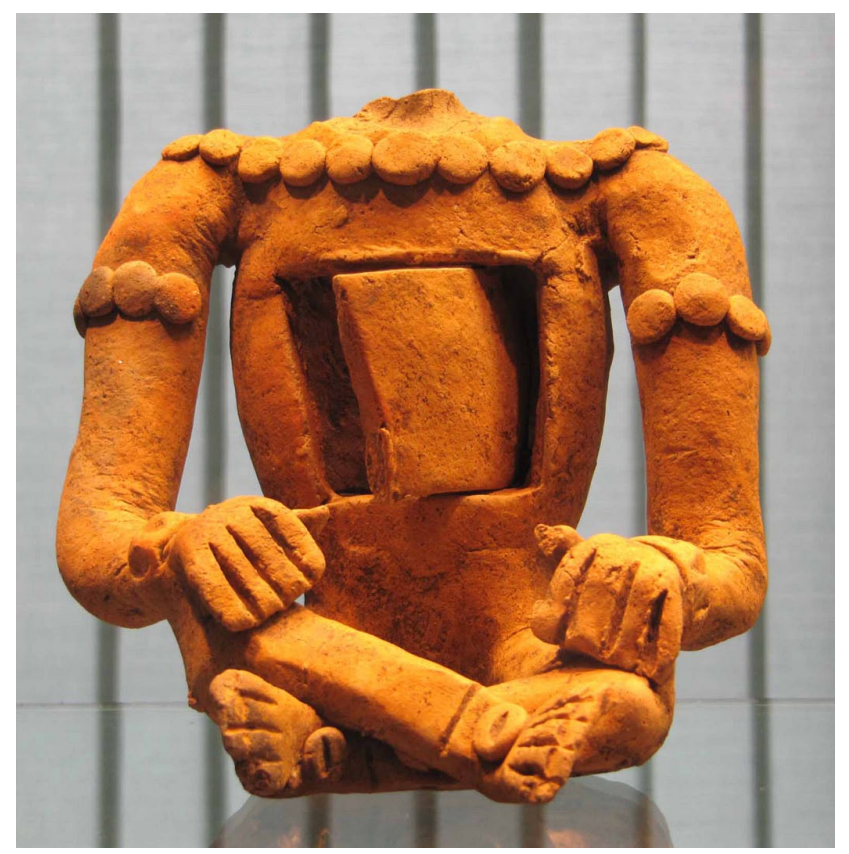

Figura 3c:HF10. Ethnologisches Museum Berlin. IV Ca. 42249 a b. $13 \times 13 \times 12.5 \mathrm{~cm}$. Fotografía de A. Villalonga. 


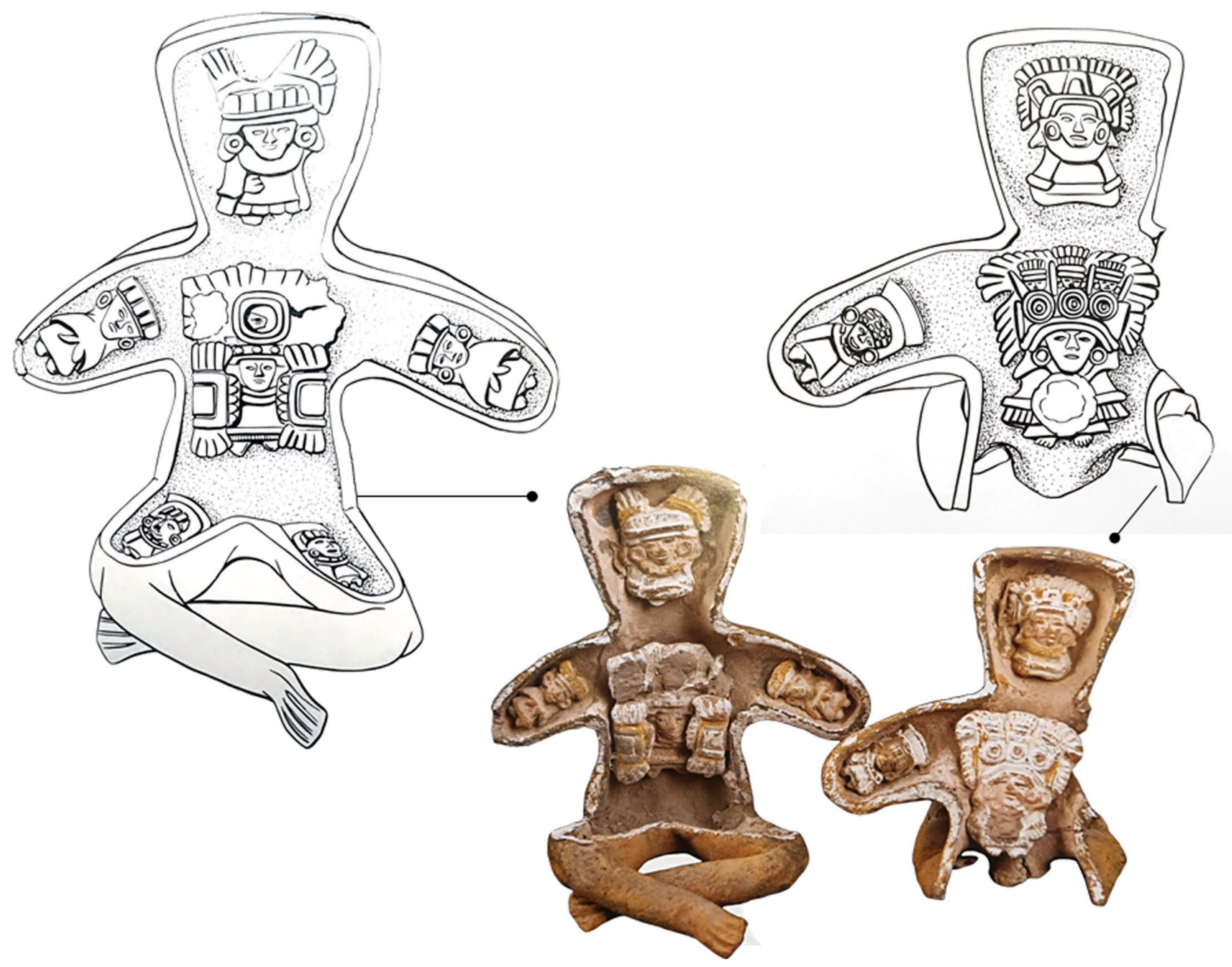

Figura 4a: HF 2. Museo Anahuacalli Diego Rivera. Catálogo: 671PJ 1316/671 PJ 1318. $8.2 \times 10 \times 5.5$ cm. Imagen tomada de: VV.AA. Catálogo Teotihuacan Cité des Dieux (2009), cat. 109, p. 299. Dibujo y montaje a partir de Sejourné (1966: fig. 193)

de Sitio y el HF2 (Figura 4a) del Museo Anahuacalli. En ambos casos se caracterizan por la ausencia de rasgos faciales y así se nos muestran insólitamente anónimas. No presenta tampoco indicios de pintura corporal a excepción de lo que parece ser en la HF5 (Figura 4c) algunos restos de pintura negra o tal vez de combustión en la parte izquierda del torso y abdomen.

Un ejemplar el HF7 (Figura 3b) presenta lo que aparentan ser seis escarificaciones circulares en relieve, en cada uno de los hombros, aunque en ambos casos alguna parece que se fragmentó y fue sustituida, posiblemente por el coleccionista, por una bolita de algodón. Presenta asimismo deformación craneal en forma de corazón muy acentuada con un pequeño orificio circular en la parte posterior. Se han representado las orejas pequeñas a ambos lados, los ojos vaciados y la boca abierta con los dientes representados en bajo relieve sin mostrar mutilación dental. No lleva ningún otro atuendo más.

Otro conjunto presenta una deformación craneal también en forma de corazón pero menos pronunciada. Se trata del ejemplar HF9 (Figura 5b) que no lleva ningún elemento en su indumentaria, presenta además las orejas con un par de perforaciones cilíndricas en la base, tal vez para las orejeras. Destacamos de esta figura también el hecho de presentar los ojos vaciados con la pupila más ahuecada, lo que da a suponer que posiblemente también llevó incrustaciones. También a este grupo con presencia clara o visible de deformación ligera en forma de hendidura en el centro pertenece el ejemplar HF6 (Figura 3a). Puesto que se trata de un fragmento, la inferencia que en 


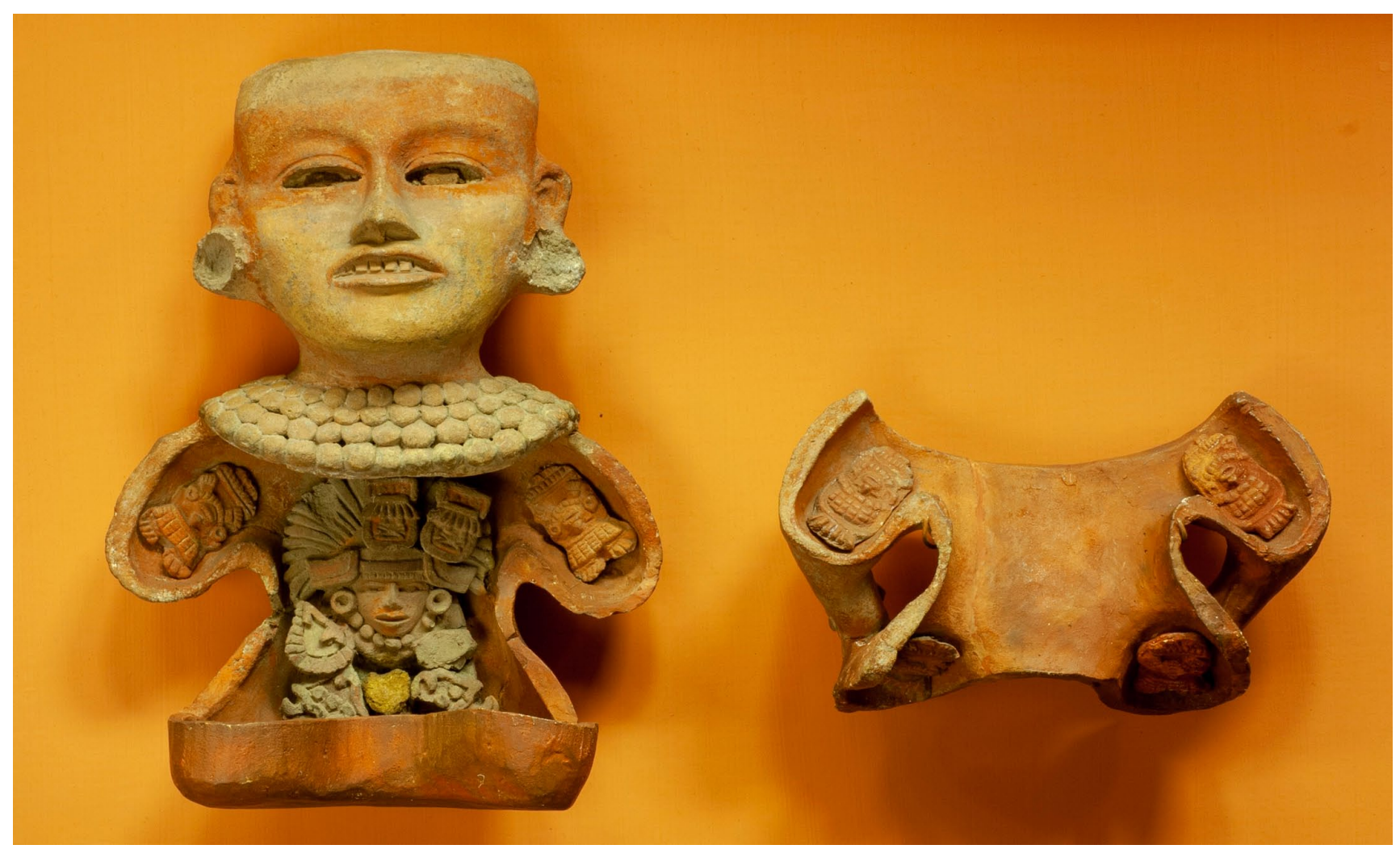

Figura 4b: HF 3. American Museum of Natural History (AMNH), Nueva York. Catálogo: 30.1/9188. $19 \times 14 \times 9 \mathrm{~cm}$. Imagen facilitada por el AMNH.

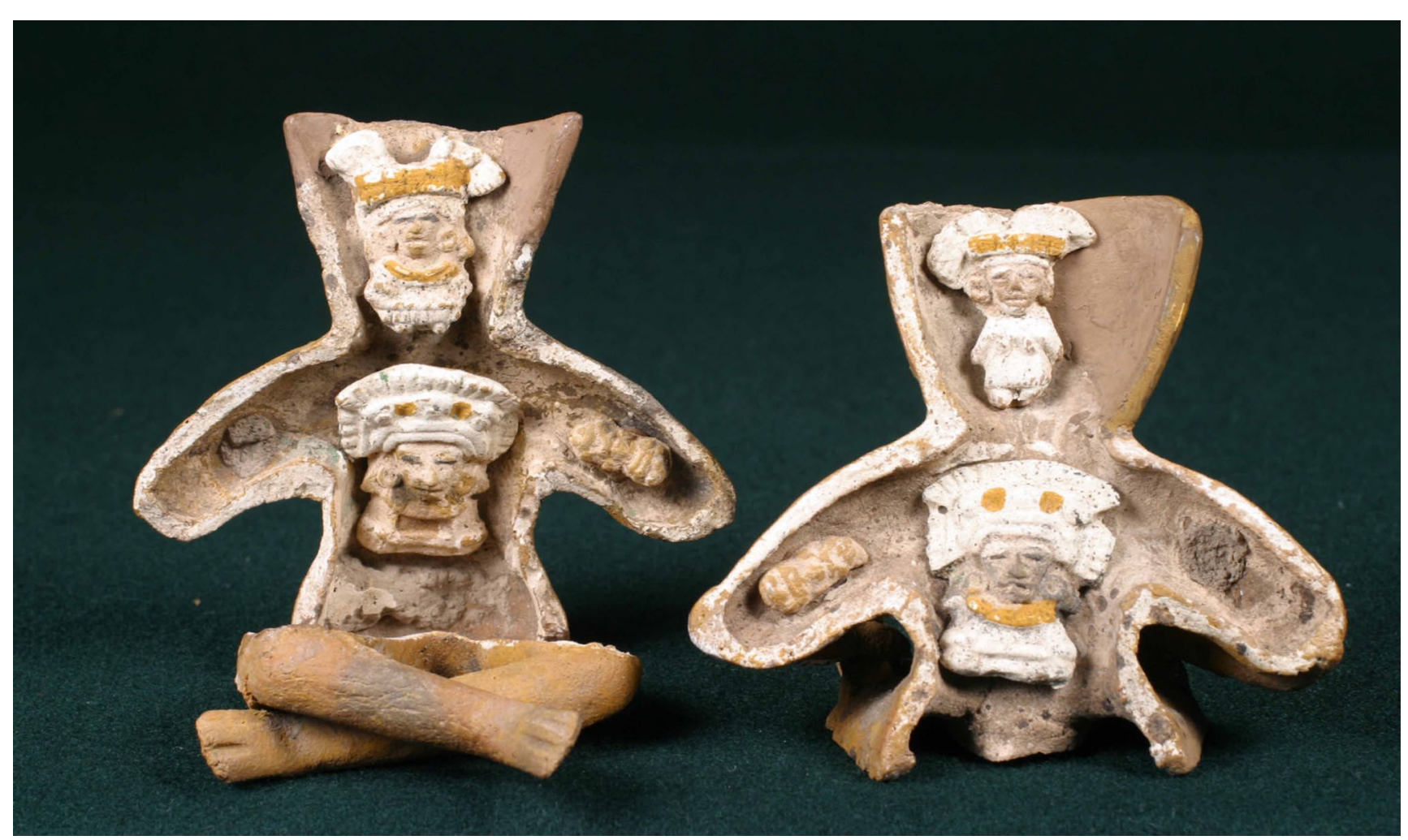

Figura 4c: HF 5. Museo de Sitio, Teotihuacan. INAH 10-412631 0/2. 14 cms. Fotografía: Miguel Morales. 


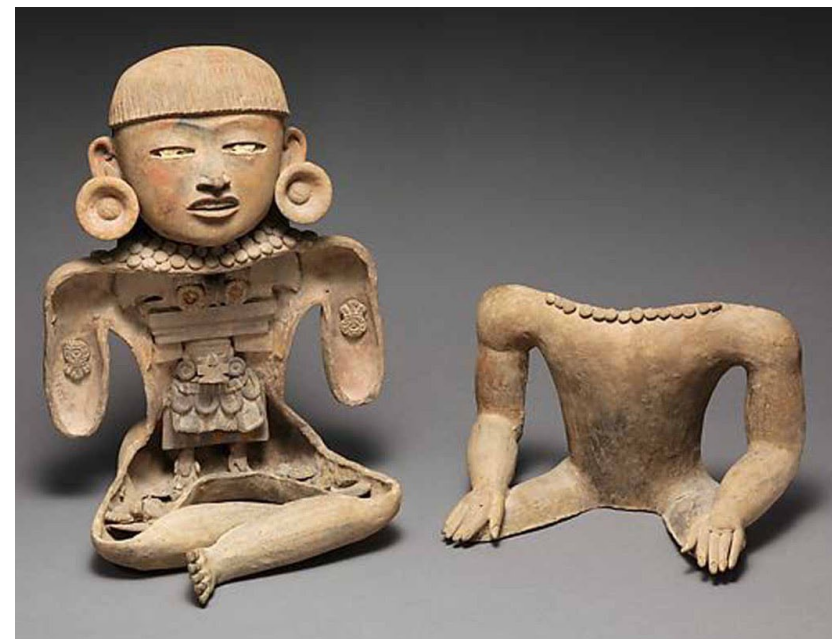

Figura 5a: HF8. Metropolitan Museum of Art. 2015.226a, b. 37.5 × $27 \mathrm{~cm}$. Retocada a partir de la imagen facilitada por James Doyle. Assistant Curator, Art of the Ancient Americas.

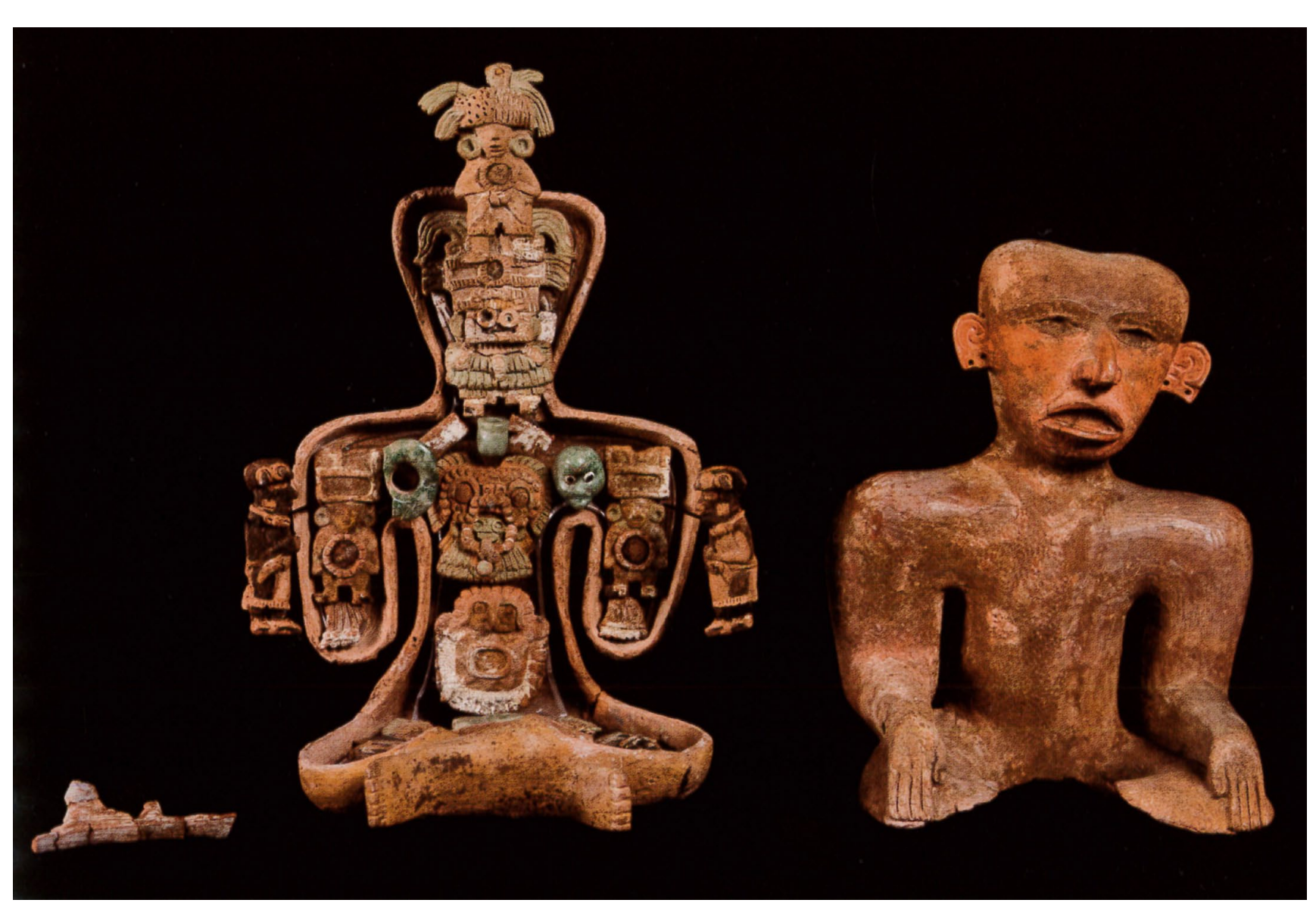

Figura 5b: HF9. Museo Regional de Yucatán "Palacio Cantón” Mérida, México. 10-251140 0/41.22 × 16.2 × 18 cm. Tomado de VV.AA. Catálogo Teotihuacán. Ciudad de los Dioses (2011:fig. 155). este apartado hacemos sólo refiere los ojos elípticos vaciados y restos de pintura en distintas partes del cuerpo y rostro. Aparecen representadas las orejas a ambos lados de la cabeza. La izquierda está más deteriorada y en la base de la derecha se detectan las huellas, de lo que podrían haber sido orejeras. La boca está abierta, pero no se representan los dientes.

Un tercer grupo lo conforman tres ejemplares que presentan rostro trapezoidal sin acusar la hendidura en el centro. Se constituye por el ejemplar HF4 (Figura 2b), HF3 (Figura 4b) y el HF1 (Figura 2a). En el primer caso, el HF4 además presenta en el empeine de los pies adornos y en las muñecas lo que parecen ser pulseras. También aludir a posibles escarificaciones o adornos que podrían haberse despegado de la figura, éstas se aprecian especialmente en las huellas dejadas en el hombro izquierdo. La figura posee además restos de pintura corporal amarillo-ocre en el cuerpo y en el rostro una faja horizontal de pintura roja sobre los ojos que impregna hasta parte de la frente de la figura. Los ojos conservan incrustaciones de pirita y parece llevar orejeras rectangulares. 


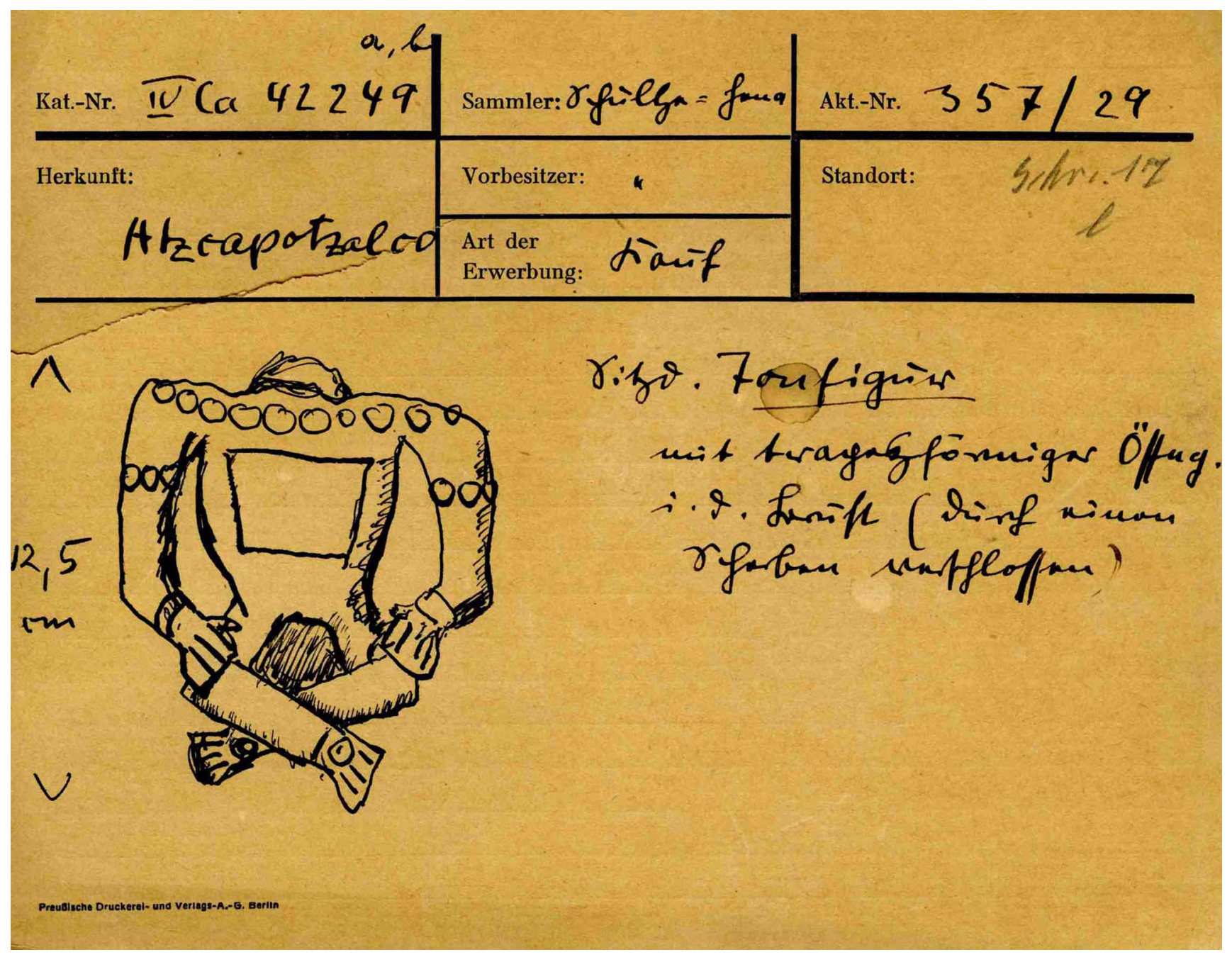

Figura 6: Cédula del Ethnologisches Museum Berlin con los datos de adquisición de la pieza HF10 (Figura 3c) a Leonhard Schultze-Jena en 1931.

El ejemplar HF3 (Figura 4b) presenta las orejas ornamentadas con orejeras circulares, boca abierta mostrando los dientes, de nuevo sin mutilación y ojos rasgados con incrustaciones de mica o pirita. Este ejemplar posee además una faja horizontal de pintura roja sobre los ojos. Asimismo como elemento singular, destaca un collar de cuatro vueltas compuesto por elementos circulares planos.

Finalmente el ejemplar HF1(Figura 2a) presenta pintura facial roja hasta la frente. Las orejas, aunque fragmentadas, se han representado a ambos lados de la cara. Cabe mencionar que en este ejemplar, la cara se constituye a partir de una máscara. Es el único conocido que tenga este rasgo, de manera que la máscara pivota sobre el cuerpo ${ }^{8}$. En la boca abierta se han representado los dientes, sin evidencias de mutilación.

Como se ha notado en todos estos ejemplares la cabeza está rasurada, no lleva tocado ni peinado y están desnudos a excepción de los ornamentos ocasionales que pueden llevar.

8. Carlos Múnera (1991:335-341) en curso del Proyecto Arqueológico Teotihuacán 80-82 excavó una ofrenda cerámica procedente de un entierro primario infantil que representaba un bulto mortuorio. Cabe mencionar como la pieza comparte algunas semejanzas con respecto a las host figurines, a pesar de que no existen las extremidades. El rostro ausente recuerda al ejemplar HF2 o el HF5, aunque una máscara cerámica fue colocada sobre éste y la oquedad rectangular en el pecho se asemeja a los ejemplares analizados. No obstante no hay mención a que en su interior se hallaran figurillas, si bien el autor sugiere que dicha oquedad tendría "[...] el fin de depositar en ella algún objeto complementario." (1991:338). 
Un ejemplar que incluímos en este estudio es el HF8 (Figura 5a), que si bien procede de Escuintla y fue manufacturado en la región del Pacífico de Guatemala, se relaciona estilísticamente con las host figurines teotihuacanas. Este ejemplar posee restos de pintura roja en el rostro y en distintas partes del cuerpo, así como de pigmento negro en parte delantera del torso y brazo izquierdo. La figura presenta orejas más naturalistas y orejeras muy grandes, circulares a ambos lados. La boca se representa abierta, con los dientes realzados y tal vez pintados de blanco. Los ojos más elípticos muestran aún restos de pirita. Esta figura además lleva el pelo largo, con un corte recto con flequillo inciso sobre la frente y la melena que cae por detrás, hacia los hombros. Notamos que hay una perforación en la parte posterior de la cabeza. La figura lleva como atuendo un collar de cuentas de tres vueltas, similar al que presenta el HF8. (Figura 5a)

El ejemplar HF10 (Figura 3c) no ha conservado la cabeza, pero evidencia huellas claras de que podría haber sido muy similar a la disposición del HF4 (Figura 2b). Presenta adornos circulares con incisión en el centro, en el empeine de ambos pies, pulseras en las muñecas y adornos circulares planos en la parte superior de ambos brazos así como un collar de una sola vuelta. Incluso el nicho del torso es en forma trapezoidal, igual que el HF4. Las dimensiones de ambas piezas también son semejantes.

\section{Las figurillas huéspedes: acercamiento iconográfico}

Nos acercaremos ahora a analizar todas las figurillas que integran el interior de las host figurines. Considero de crucial importancia analizar estos contenidos para contribuir a esclarecer la interpretación de estas figuras, ya que dudo que se pueda ofrecer una explicación unilateral al respecto dada la variabilidad detectada en las anfitrionas. Al respecto mencionar que excluimos en esta sección la HF9 y 10 por motivos distintos. La HF9 fue excavada en el interior de la Estructura XIV de Becán (depósito
69-2) por J.W. Ball (1974) y ha sido objeto de análisis exhaustivo y publicaciones recientes (Bonnafoux et al., 2011). La HF10 (Figura 3c) no ha conservado figurillas en el interior por lo que se descarta también".

HF1. (Figura 2a). Se ha conservado la figurilla adosada a la cara interior de la tapadera trapezoidal. Representa una mujer ricamente ataviada con quechquemitl que deja entrever sus manos por debajo. Lleva un collar de banda pintado de verde, orejeras circulares pintura facial naranja y tocado rectangular de banda de plumas con flor en el centro. Puesto que este ejemplar de host figurines se encontró en contexto arqueológico en el apartado siguiente se hará mención a la distribución de las 11 figurillas hechas a molde policromadas que se hallaron dispuestas junto a esta ofrenda y que permiten inferir algunas interpretaciones. Es muy posible que éstas se encontraran originalmente en el interior de la anfitriona. De las figurillas dispuestas 7 de ellas son del tipo "half conical" con brazos ausentes o que se introducen dentro del cuerpo cubierto con túnica y con un elaborado tocado ${ }^{10}$. De éstas siete, dos presentan el mismo tipo de tocado de plumas, ojos, antenas y probóscide de mariposa ${ }^{11}$, además de una fila de gotas de agua que cae sobre la frente de la figura. Estos ejemplares presentan policromía idéntica en el tocado donde se encuentran representados el ocre, rojo, blanco y gris ${ }^{12}$ para formar las distintas partes, con lo que su aplicación podemos deducir que es codificada. Otro conjunto de 3 figurillas "half conical" que también presentan la túnica o vestido que cubre le cuerpo, presentan los mismos rasgos iconográficos: un tocado similar a lo que Sejourné definió como posibles sombreros (1966: fig. 39, f y h) formado por un tocado de bandas horizontales con elemento circular o nudo en el centro y en su remate superior un elemento tubular en apariencia semirígido en el lado izquierdo que se proyecta hacia fuera y sobresale del cuerpo de la figura y un contrapeso en el extremo derecho. El tocado y el sombrero son rojizos, la cara pintada de ocre y el vestido en blanco grisáceo menos las dos vueltas inferiores circulares que son de color ocre.

9. Maria Gaida, Ethnologisches Museum Berlín (comunicación personal, 20/05/2019). La pieza fue comprada en 1931 por Leonard Schultze-Jena en Azcapotzalco.

10. Para algunos autores esta túnica o vestido identifica a figuras masculinas (Sejourné 1966:145), para otros es un vestido que corresponde al género femenino (Cabrera 1993:211, cat.61). A. Headrick (2007) interpretó estas figuras "half conical" como representaciones de bultos mortuorios.

11. Casco en forma de mariposa. Véase tipos y variantes en Sejourné (1966: 179-181, fig. 124-126).

12. Cabrera Castro (1993: 211, cat. 61) indica que es verde, intuyo que en función de la publicación los tonos aparecen más verdosos o más grisáceos. 
Otro conjunto de dos figurillas presentan una especie de yelmo acolchonado o casco estriado, con un remate semicircular encima pintado de negro y remate superior de plumas en blanco grisáceo. Este tipo de tocado es similar al que Sejourné identifica como uno de los tipos de coronas (Sejourné 1966: fig 43e). El vestido cónico evidencia restos de pintura rojiza, igual presente en el rostro exceptuando en el cuello que aparece pintado de ocre. Otros tres ejemplares constituyen un cuarto grupo: posición sedente con las piernas abiertas o cruzadas (solamente un ejemplar se conserva completo, los otros están parcialmente fragmentados), collar de banda en el cuello, taparrabo o maxtlatl. Las cabezas parecen llevar el pelo recogido y en el remate superior un tocado semicircular de plumas de las que sobresalen por delante cinco rojizas que destacan del fondo grisáceo del tocado y del borde externo pintado en ocre. Finalmente comentar el último ejemplar aislado, es decir, aunque es semejante en posición del cuerpo sentado que el grupo anterior, no comparte el mismo tipo de tocado y es un jorobado (Cabrera 1993:211, cat.61): éste se compone por una flor de cuatro pétalos y en su remate superior un tocado corto de plumas con chalchihuites dispuestos en una faja horizontal. Los jorobados aparecen representados entre las figurillas de barro teotihuacanas. Sejourné (1966: lám 56, p. 247, lámina165) sugirió relaciones directas con el dios Nanahuatzin. Silvia Trejo (2007:19) sostiene que algunos mitos cuentan como la diosa Xochiquetzal engendró junto a Pilzintecutli a este dios y que en Tamoanchan era atendida por varias diosas y la cuidaban enanos, jorobados y otros seres. También C.E. Tate (1993:16) sostiene como entre las civilizaciones Mayas y Aztecas, los jorobados y los enanos servían en las cortes regias como mensajeros especiales que podían traspasar la barrera del inframundo. Sin duda llama la atención la presencia de este jorobado y su posible relación con la anfitriona y con el mundo del más allá.

Sin duda estas figurillas a las que podemos agrupar en conjuntos de dos figuras o tres, forman un grupo consistente que comparte la misma iconografía, misma aplicación cromática y, en consecuencia, representan la misma entidad. En una segunda fase de esta investigación (artículo en preparación) ofreceremos algunas propuestas al respecto.

HF2 (Figura 4a). Las figurillas que residen en esta anfitriona son un total de 9. Es probable que hubiera alguna más, ya que nótese que la anfitriona en su sección frontal está fragmentada y le falta un brazo, lugar donde con toda seguridad, se localizaría, si partimos de la acusada distribución espacial simétrica de las figurillas, otro ejemplar. Iniciando el recorrido por la sección frontal, la figura que ocupa la cabeza es más volumétrica, es un tipo de figurilla designada como "half-conical" o de base cónica y todo su cuerpo queda oculto debajo de la indumentaria. Lleva un collar de banda pintado de ocre, orejeras circulares y un complejo tocado con tres elementos trapezoidales centrales con remate superior de plumas. La figurilla que descansa debajo de ésta, presenta un tocado de chalchihuites con cuatro elementos verticales que separan a su vez tres rostros frontales, ataviados con orejeras y con sus respectivos tocados de plumas. Predomina el blanco a excepción del color ocre para partes del tocado. No puede apreciarse si la figura llevaba adherido algún otro material a la altura del pecho, pero la huella que ha dejado, evidencia falta de pigmento en este sector. La figurilla que se conserva en el extremo del brazo es femenina, lleva collar de banda y encima uno tubular, orejeras y un tocado de tipo acolchado. Prácticamente toda la figura que interpreto como femenina, por la presencia de falda y capa, presenta todo el cuerpo pintado en blanco, a excepción de la parte inferior del tocado y el rostro, en amarillo-ocre. De la sección posterior del cuerpo destacan las dos figurillas centrales: la que ocupa la cabeza con tocado de plumas, orejeras cilíndricas, collar de banda, falda y capa y la que se encuentra justo en la zona de central del tórax, que presenta un tocado de plumas al que seguramente se adhirieron en el centro otros elementos, posiblemente apliques o adornos. La figura además sostiene dos escudos rectangulares con plumas en los extremos. De manera general comentaremos que las 4 figurillas a molde que se encuentran en las extremidades son femeninas: visten falda y capa, en el caso de las extremidades superiores, ésta además se anuda en el centro.

HF3. (Figuras 4b, 7a, 7b). En esta anfitriona se localizan un total de 9 figurillas, siendo una de ellas de mayores dimensiones y ocupando la posición central del nicho. Esta figura interior ha sido identificada por algunos autores (Barbour,1993:213) como masculina. Destaca porque ocupa la posición central entera y muestra alas de mariposa en los extremos, un elemento central que, tal vez por su huella circular y el color ocre, podría corresponder a un espejo de pirita. La figura lleva collar de cuentas de cuatro vueltas, orejeras circulares y un tocado con fondo de plumas sobre el que se disponen dos 

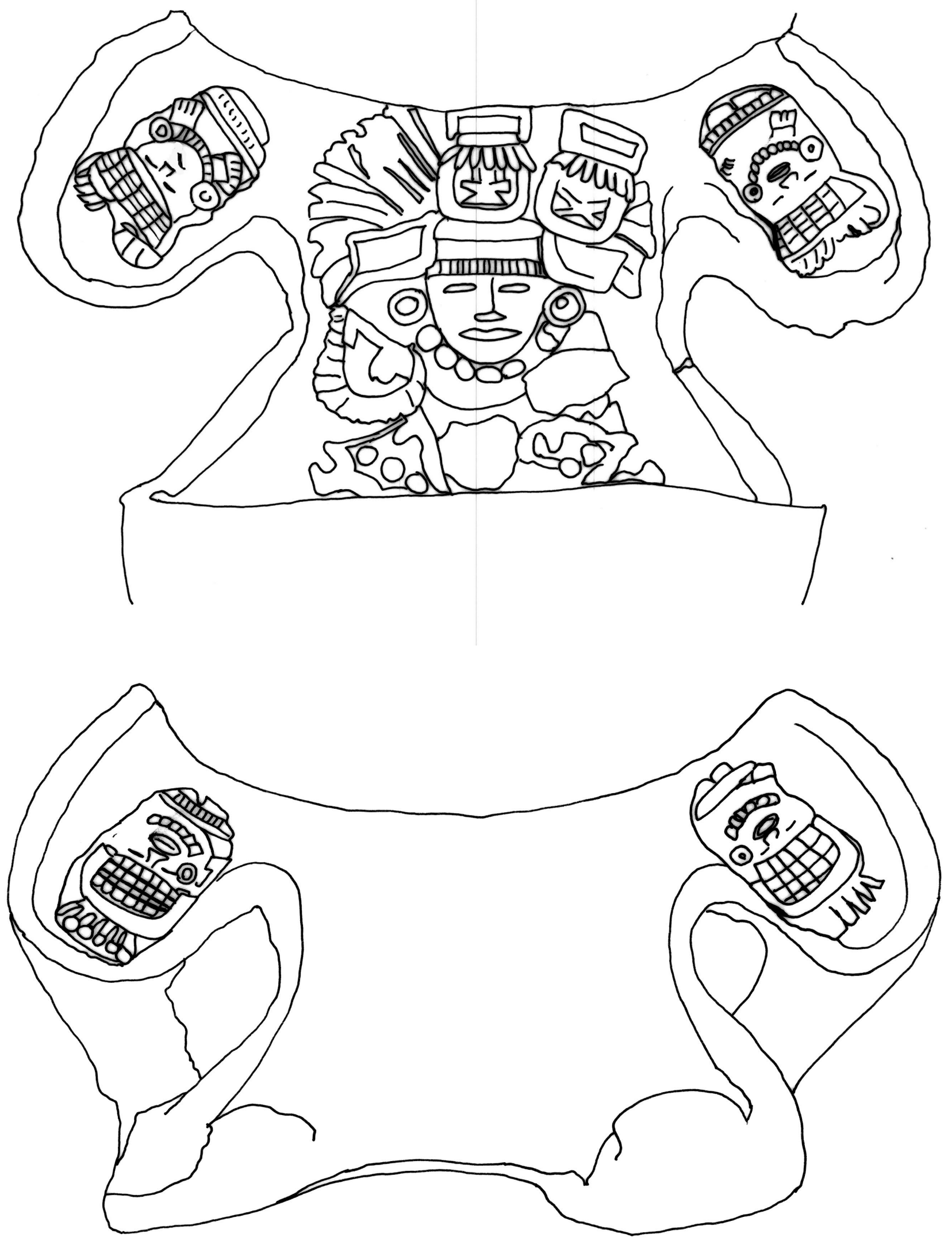

Figura 7a y 7b: Detalle dibujado por A.Villalonga del interior de la HF3 (Figura 4b). 
medallones que tal vez representen conchas estilizadas en cuyo interior se representa una placa bucal ${ }^{13}$ o nariguera poligonal en forma de mariposa estilizada y en la parte superior una banda rectangular con tres círculos. Cabe mencionar que se asemeja a la plaquita moldeada con nariguera como basamento de un templo que publicó Von Winning (1987, T.II, 6,a.). Tal como señaló el autor (1987:59-60) no es posible determinar si el motivo iconográfico de la placa bucal deriva de una estilización del talud-tablero, dada su semejanza o si se trata de una coincidencia. La policromía de esta figura es extraordinariamente variada, aunque siguen dominando el verde, el rojo y el blanco, para sus distintas partes. Las ocho figurillas a molde que se encuentran distribuidas en las extremidades deben estudiarse igualmente en detalle. Solamente dos, que se localizan debajo de la tapa que cubría las piernas, no son visibles y no las podemos analizar. Barbour identificó que dichas figurillas eran masculinas y femeninas, aunque no determinó más que la indumentaria era el indicador ${ }^{14}$. Precisaría que en este caso es el tocado lo que le permite a Barbour discriminar el género, ya que la indumentaria es muy semejante entre ellas. Aquellas que se encuentran en la sección posterior corresponden a representaciones femeninas, llevan un tocado de banda con estrías y dos remates semicirculares o redondeados en los extremos superiores. Las figurillas de la sección anterior, son masculinas ya que llevan un tocado semejante al yelmo acolchonado con remate de plumas superiores. Las dimensiones de las figurillas no superan los 4 centímetros y la policromía observada no permite identificar más que color ocre y rojizo.

HF4. (Figura 2b). La única figurilla que reside en la parte central del nicho lleva falda y huipil pintado en blanco, un collar de banda en tonos ocres, dos orejeras circulares y tocado estriado pintado de ocre. Nótese asimismo como el rostro está pintado de rojo.

HF5. (Figura 4c) Las seis figurillas que la integran son similares a las que se encuentran en HF2 (Figura 4a). En esta ocasión, tanto la sección anterior como posterior parece que una figura del tipo "half conical" ocupa en eje central, el tocado lleva tres elementos circulares y se remata superiormente por plumas. En el tocado de la figurilla posterior se aprecia que si bien el blanco dominaba, también hay círculos en amarillo. La figura superior lleva huipil y falda, collar de banda, orejeras y, aunque el detalle no permite una observación muy detallada, recuerda la representación de un penacho en uno de los lados y de un pájaro (¿quetzal?) en el otro. El tocado en la parte baja está pintado en amarillo y blanco para la parte superior. La figura superior de la sección anterior es similar a su homónima anterior, aunque está prácticamente toda pintada de blanco, a excepción de la parte baja del tocado que destaca en ocre.

Llama la atención de estas huéspedes que las que ocupan las extremidades superiores son diminutas y casi no se han esbozado los rasgos. Una huella dejada, tanto en la sección anterior como posterior interna del brazo derecho de la anfitriona, indica que posiblemente dos figurillas menores ocuparon ambos lugares, de modo que tal vez hubieron 8 figurillas en la parte del tronco. Se desconoce si en las piernas se podían haber alojado figurillas, probablemente dos, siguiendo la disposición simétrica que venimos analizando, sin embargo hay escasos datos al respecto de este ejemplar.

HF6 (Figura 3a). La figurilla del torso llena todo el nicho y se sitúa en el eje central. Es femenina atendiendo a falda y quechquemitl, con una capa encima de color azul. Como ornamentos lleva orejeras circulares, collar de banda con cuentas encima y un tocado en el que destacan tres flores de cuatro pétalos con resplandor de plumas hacia fuera. La flor presenta tonos ocres, exceptuando el centro que se pintó de rojo. La base del tocado de plumas es blanco. El fondo se completa por un tocado de plumas en blanco ${ }^{15}$. Quisiera evidenciar que a pesar de que Barbour (1993:214) mencionaba en relación a este sujeto que no es frecuente que una figura femenina se encuentre en la zona central, ya que suelen estar en el pecho y en las extremidades, quisiera evidenciar como el análisis que acabamos de comentar que la HF4 (Figura 2b) o la HF2 (Figura 4a) lo descartan por poner un ejemplo.

HF7 (Figura 3b). En esta anfitriona se conservan dos figuras. La figura que se encuentra detrás de la tapa es femenina: lleva huipil y falda, presenta tocado de banda con elemento circular en el centro, flor, orejeras

13. Siguiendo a Von Winning (1987:59) la placa bucal puede ser de dos tipos: la que designa como "nariguera poligonal" y la "bigotera o banda labial de Tláloc". Suele considerarse un atributo habitual en imágenes antropomorfas del Dios Mariposa (1987:T.I, 123). Por el contrario A. Caso (1966:258-259) asocia la nariguera escalonada (yaca papalotl) o "mariposa de nariz" a los símbolos asociados con el agua.

14. "The smaller figurines in the legs and arms are simply dressed females and males." (Barbour, 1993:213, cat. 63).

15. Von Winning (1958:53) especifica los colores. 


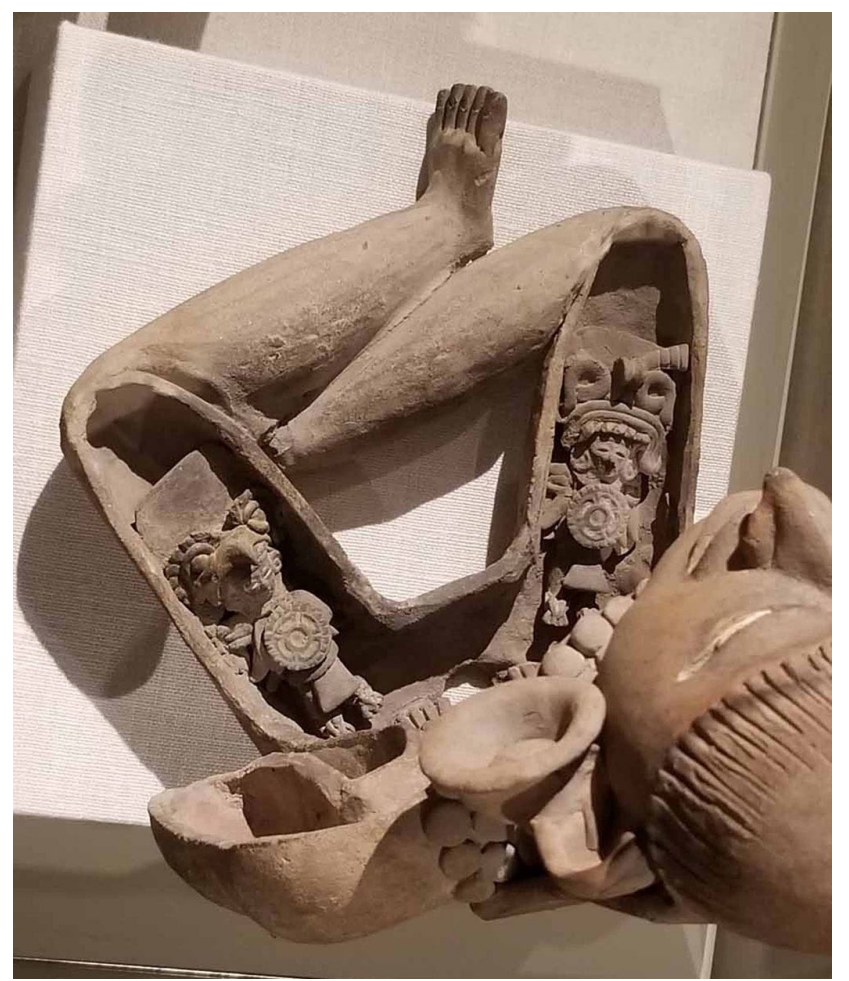

circulares, collar y sujeta a ambos lados, con una disposición que recuerda a las figurillas que sostienen los escudos, tres elementos verticales unidos por dos círculos concéntricos. La figura presenta tocado, orejeras, collar y los elementos sustentados en azul. Cabe mencionar asimismo que la figurilla interior no está hecha a molde, sino a mano a diferencia de las analizadas hasta ahora. Tiene mayor corporeidad y muestra lo que parece ser un guerrero ya que con la mano izquierda sostiene un escudo trapezoidal o cuadrangular y con la derecha alza en alto una arma tipo maza ${ }^{16}$. Los ojos y boca de la figura presentan restos de pintura blanca. Lleva orejeras y un collar de cuentas azules, así como ornamentos en el empeine y tobillo pintados también en azul.

HF8 (Figuras 5a, 8a, 8b). En este caso cabe mencionar que no analizaremos la figurilla de la sección anterior puesto que faltaba y según W. Barbour (1993:215, cat. 66) fue reconstruida siguiendo el modelo de la figurilla de la posterior. La figura ocupa todo el centro de la figura, igual por ejemplo que la HF3 (Figura 4b).

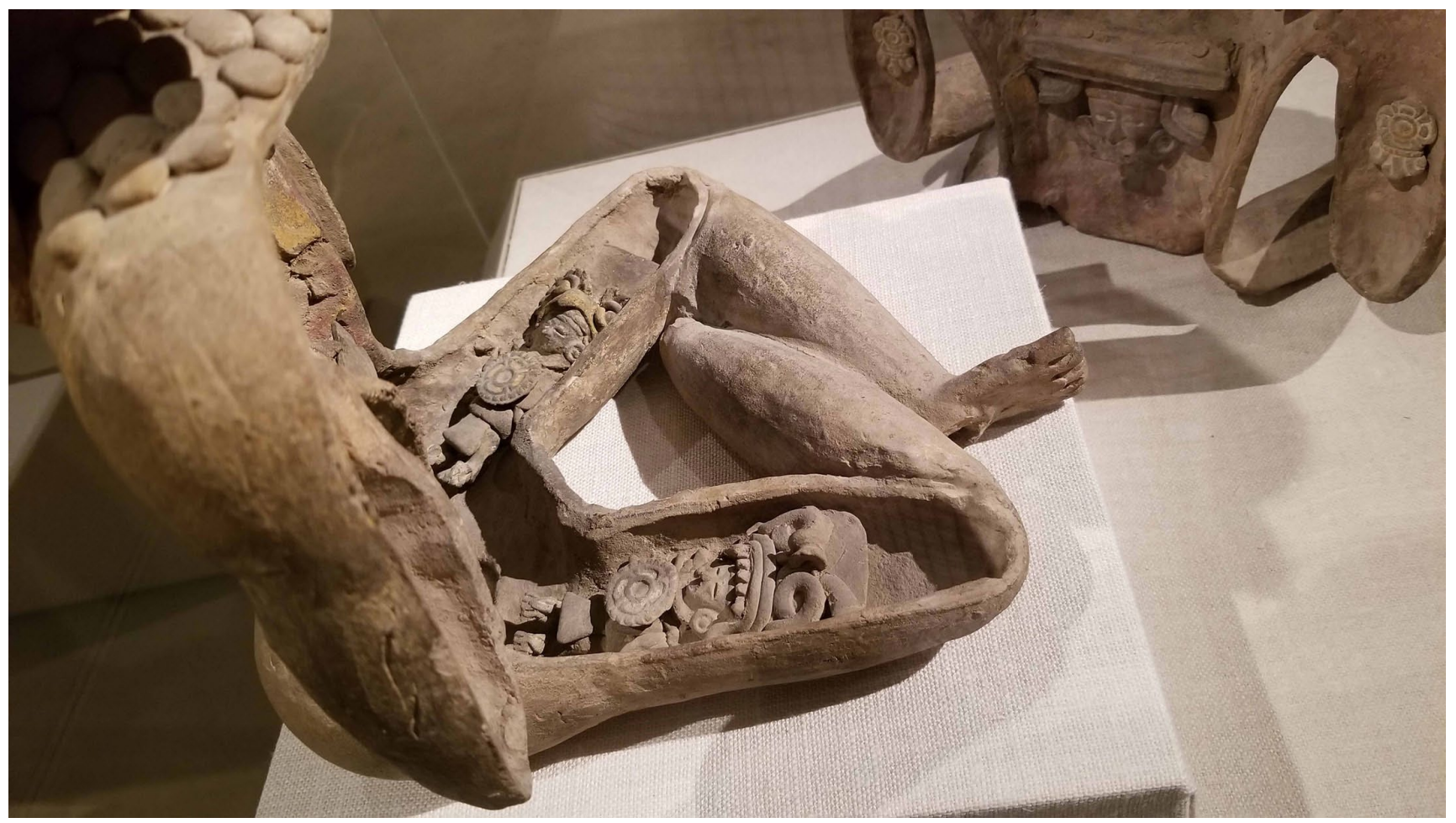

Figura 8a y 8b: Detalles del interior de la HF8. (Figura 5a). Fotografía: James Doyle. Assistant Curator, Art of the Ancient Americas. Metropolitan Musem of Art.

16. Marco A. Cervera Obregón (comunicación personal 20/05/2019) sugiere que va armado más como guerrero del Occidente de México que con armas teotihuacanas, si bien los escudos rectangulares son más propios de Teotihuacan no son exclusivos. Aunque en la antigua urbe se han recuperado cabezas de maza, al parecer tampoco era el arma más común, a diferencia del Occidente de México. Ambos sospechamos de la autenticidad de la pieza. 
Lleva un tocado de tipo arquitectónico, tal vez un templo estilizado y encima de éste una referencia clara a la mariposa, con los ojos circulares en ocre, emplumados y la probóscide. La figura lleva un flequillo recto, que cae debajo del tocado, imitando a la anfitriona, placa bucal o nariguera, orejeras circulares y un atuendo peculiar compuesto por tres vueltas de collar de placas cuadradas y un vestido inédito compuesto por cuatro medallones semicirculares sobrepuestos a tres (aunque solamente se conserva uno y huella de otro) solapas rectangulares colocados encima de una placa o base. Las piernas de la figura se ven por debajo del vestido y lleva sandalias y ornamento en los tobillos. A diferencia de los casos analizados previamente, en los brazos no aparecen figurillas huéspedes antropomorfas, sino que en este caso se han sustituido por medallones con la flor de cuatro pétalos y tres volutas, que habitualmente aluden al agua o bien a la sangre. En las cavidades que ocupan las piernas se han identificado dos figurillas también distintivas: ambas son masculinas, con el maxtlatl, ornamentos en las sandalias y llevan en el pecho un aplique en forma de medallón circular con la imagen de la flor de cuatro pétalos. Las dos figuras se distinguen por llevar en la cabeza un elaborado casco, una de ellas en forma de ave, con ojos emplumados y pico. La otra lleva el tocado hecho a mano con dos tiras redondeadas que conforman los ojos o anillos en los ojos, una probóscide y en la parte inferior unos labios con los extremos doblados hacia arriba y con una fila de dientes debajo, características propias del Tlaloc B o Tlaloc-Jaguar (Pasztory: 1974, Von Winning 1987:T.I, 95), dios tutelar del complejo Guerra/Sacrificio. La presencia de la probóscide nos llama la atención; es un elemento iconográfico propio de la mariposa, no del dios Tláloc B, pero sigue siendo un rasgo asociado a la simbología mortuoria. Analizando las dos figuras huéspedes masculinas con sendos tocados, considero que aquí se están representando los precedentes de las órdenes militares de los caballeros águila y jaguar del Posclásico, cuya existencia ya intuía Von Winning (1987:T.I, 169). Cabe mencionar asimismo que la mayor parte de las figurillas se han elaborado a mano, aunque posiblemente se utilizando moldes para algunos detalles como los apliques. Esta variación en los motivos iconográficos así como en la técnica de manufactura, de tipo regional, es propia de los talleres alfareros de Escuintla ${ }^{17}$, de dónde procede la pieza referida.
Analizando en común algunos de los rasgos compartidos entre las huéspedes podemos señalar algunas constantes.

Código cromático. El uso de los colores si bien es variado, su aplicación parece seguir una constante entre ocre, rojo, negro, blanco y verde/azul. Cabe señalar al respecto que el color es poseedor de significado semántico como ya ha sido demostrado en otros estudios (Dupey, 2006, 2009, 2015). Es muy probable que la aplicación concreta de determinados colores en las huéspedes apunte a direcciones que sin duda deben ser analizadas con mayor profundidad. En este caso se ha observado también que algunos ejemplares de anfitrionas, como es el caso de la HF1 (Figura 2a), que presenta el rostro pintado en rojo, la HF3 (Figura 4b) con una franja o banda también en rojo en parte de la frente y en los ojos, así como la HF4 (Figura 2b), HF8 (Figura 5a) o la HF9, presentan asimismo restos de pintura facial en rojo. Testard y Serra Puche (2011:239) basándose entre otros elementos distintivos como los tocados y en la aplicación simbólica de pintura facial en las figurillas del sitio epiclásico de Xochitécatl, Tlaxcala, identificaron la presencia de figuras proto-Tlazoltéotl y proto-Xochiquetzal. En nuestro caso, la ausencia de otros atributos nos impide proseguir con su identificación. Por el momento, ante la ausencia de atuendo distintivo y tocados en las anfitrionas, propongo que la desnudez y asexualidad pudieran haberse identificado con lo divino, ya que a falta de atributos que permitan corroborar que se trata de dioses, tal vez deberíamos considerar que son expresiones de lo divino. La presencia de la banda roja o pintura facial aplicada en algunos de los rostros de las anfitrionas podría considerarse tal vez un indicador de una forma precursora de esta deidad. En el Posclásico la diosa Xochiquetzal tiene muchos elementos que se vinculan a ella: la fertilidad, la guerra, el sustento, pero también la muerte. Como señalaba M.J Rodríguez-Shadow: "[...] según la Historia de los mexicanos por sus pinturas, ella fue la primera mujer muerta en la guerra, y quizá por eso se le [sic] asociaba también con la muerte, era considerada una Cihuatéotl." (1997:428)

Las incrustaciones oculares. Además algunas de ellas, tal como sucede en la litoescultura antropomorfa teotihuacana (Villalonga 2014: 507-509) muestran o bien los ojos huecos o vaciados (HF1, HF6, HF7, HF9), sin rostros 
(HF2, HF5) o los ojos rellenos con restos de incrustaciones de pirita o mica HF3, HF4, HF8). La pirita de hierro fue usada como espejo en Mesoamérica, tanto formando parte de la indumentaria como en los rituales adivinatorios. Tal como sostiene K.Taube, en Teotihuacan si bien hay escasa información que describa su contexto ${ }^{18}$, “[...] mirrors were strongly identified with eyes [...] to represent the shinning pupil."(1992:181). Y más adelante concluye: "With their identification with eyes, faces and pasasageways, it is fairly clear that Teotihuacan mirrors were used in divinitation, a means of seeing into the supernatural world." (1992:198)

Símbolos recurrentes: la flor de cuatro pétalos y la mariposa. Frente a la desnudez aparente de las anfitrionas, se opone la extraordinaria variedad en la indumentaria y tocados de las huéspedes. Si bien algunas de ellas se pueden agrupar como se ha mencionado para la HF1(Figura 2a) y parecen formar un conjunto consistente, en los otros casos conservados existe diversidad aunque también se comparten algunos elementos iconográficos en los que nos vamos a detener. La flor de cuatro pétalos ha aparecido en algunos de los integrantes de las huéspedes, en algunos casos asociado al tocado $\mathrm{HF} 1^{19}$ (Figura 2a), HF6 (Figura 3a) y HF7 (Figura 3b) en otros aparece como aplique aislado en el interior de la anfitriona o en el pectoral de la figurilla como en HF8 (Figura 5a). Puede aparecer como un signo independiente o asociado al resplandor de plumas o a volutas de agua. En cualquier caso retomando a Von Winning (1987: T.II, 31-32) el uso amplio y variado del signo se vincula con la fertilidad, aunque no excluye otras interpretaciones mitológicas. En este sentido tal vez deba reconsiderarse la interpretación que Heyden hizo de la cueva de la Pirámide del Sol y el culto a la Diosa Madre. Heyden sugirió que la cueva tiene forma de flor de cuatro pétalos y "[...] simboliza la matriz materna, la creación, el lugar del surgimiento y el lugar de descanso" (1977:24).

Otro elemento recurrente que se ha detectado en el análisis es la presencia de los simbolos que representan la mariposa ${ }^{20}$ (pars pro toto) en los tocados de algunas huéspedes. Dos de las figurillas de HF1 (Figura 2a) llevaban un tocado en forma de mariposa, la HF3 (Figura 4b) presentaba también rasgos iconográficos como la presencia de alas de mariposa en la huésped que ocupaba el eje central, y destaca la HF8 (Figura 5a) también ocupando el eje central con el tocado de mariposa así como la figurilla que descansa en una de las piernas, cuyo tocado presenta la característica probóscide. Von Winning (1987:T.I, 115-123) advirtió diferencias entre la función simbólica de la mariposa representada en la cerámica y en la pintura mural ${ }^{21}$. En la primera adquiere un carácter marginal, mientras que en la cerámica ocupa un rango nominal "[...] en el que el insecto se convierte en nahual de un ser sobrenatural, el Dios Mariposa." (1987:T.I, 123). La mariposa aparece en la cerámica asociada a contextos seculares y rituales en Teotihuacan y posiblemente fue la expresión de una clase administrativa que adoptó el icono de la mariposa como su nahual. De este modo: "Individuos ataviados con elementos de mariposa representan al Dios Mariposa, la deidad titular de los mercaderes y embajadores, o sea la clase administrativa que se encarga del intercambio de productos y de la difusión de los conceptos ideológicos. Por ser viajeros en territorio hostil tenían también una función militar, lo que se expresa en la asociación de símbolos de mariposa con signos de armas." (1987:T.I, 125). El hallazgo en 1982 de un taller de cerámica para la producción de incensarios en la Ciudadela sacó a la luz más de 20.000 adornos o apliques. Por su ubicación, se sugirió que la producción y distribución de estos incensarios estuvo controlada por el Estado. En el análisis de S. Sugiyama $(1998: 5,2005)$ puede identificarse que dentro de la categoría de adornos zoomorfos, la mariposa es, sin duda, la que estaba más ampliamente representada. (Sugiyama 2005: tabla II, p.10, fotografías 23-33).

Como señalaba Paulinyi (2014:29) es frecuente la iconografía del Dios Pájaro Mariposa en las zonas de influencia de la metrópolis, especialmente en cerámicas e incensarios de Escuintla, Guatemala. En nuestro caso

18. Vid. al respecto Gazzola et al. 2016:107-124.

19. Dada la conservación de la figurilla no se puede determinar con certeza, tal vez sea un chalchihuite.

20. Los elementos lepidópteros señalados por Von Winning consisten en: "[...] dos ojos emplumados, la trompa o probóscide enroIlada en carrete, y dos antenas largas y delgadas que se curvan encima de los ojos y terminan en filamentos de manojos de plumas." (1987: T. I, 119). Vid al respecto el estudio iconográfico de la mariposa en de Sugiyama (1988:16-17).

21. En la pintura mural el propio contexto que envuelve a la figura permite análisis más prolijos, en la cerámica los elementos de mariposa aparecen más restringidos y aislados. Recientemente Z. Paulinyi (2014) revisa los elementos o signos que forman el complejo del dios en sus representaciones pictóricas y cerámicas. El signo "ojo de reptil" y "comb \& bar" no se dan en los ejemplares analizados, no obstante sí que aparece la flor de cuatro pétalos que es otro de los símbolos que lo definen. 
cabe mencionar que la HF8 (Figura 5a), procedente de Escuintla, presenta una clara iconografía asociada a la mariposa, presente en los atributos de la huésped que ocupa la posición central, así como en las figuras que se colocaron en las piernas. Además destaca el aplique circular en el pecho de ambas simulando un escudo o espejo. Cabe mencionar que este aplique circular está presente también en tres figuras huéspedes de la HF9 (Figura 5b), procedente de Becán, y se identificaron como espejos (Bonnafoux et al. 2011: 73). Por otro lado, otro elemento que llama la atención en la HF9, reside en que cabría esperar una iconografía con presencia de elementos del complejo mariposa, como su homónima foránea, la HF8 (Figura 5a), sin embargo ésta no se encuentra presente. En su lugar se representan figurillas con atributos del dios de la lluvia Tlaloc, el signo "lechuza y armas"22, identificado como la insígnia heráldica del complejo guerra-sacrificio, y una figura con tocado de felino. No hay presencia de atributos de mariposa, sin embargo por la iconografía de las huéspedes se sigue asociando igualmente todo el conjunto, a una dimensión militar. (Bonnafoux et al. 2011:73).

Recientemente señalaba C. Conides (2018:115, 2017: 112-113) que dos de las figurillas del HF1(Figura 2a) llevan un tocado de mariposa/serpiente. En su análisis de los contextos en los que aparece este símbolo en las cerámicas y representaciones pictóricas, pone en relación el simbolismo de la mariposa, tradicionalmente asociado a la guerra y al sacrificio ${ }^{23}$, a una asociación con el agua, las plantas o las ofrendas relacionadas con el agua ${ }^{24}$. Sugiere que los personajes que llevan este tipo de tocados funcionaron en contextos rituales o adivinatorios o en actividades que podrían haber conmemorado o recreado actividades (militares, sacrificiales, ritos agrícolas, etc). Sugiere asimismo la posibilidad de una institución de carácter más popular, que parece haber sido estratégica por parte del estado para mantener la cohesión entre distintos grupos en la ciudad. Esta institución seria responsable en llevar a cabo rituales centrados en la mariposa o en una deidad. Para Z. Paulinyi (2014) en su análisis de la presencia del dios en las pinturas murales de Atetelco nos lo sitúa en un contexto mítico, donde el dios resurge o renace del Inframundo, lugar de plantas, agua y muerte. Recientemente J. Nielsen (2018:94-95) ha recuperado la equivalencia simbólica de las mariposas a las almas de los muertos en base a dos elementos íntimamente vinculados: la pupa del insecto durante su metamorfosis equivale a los bultos mortuorios (Headrick 1999, Taube 2006) que eran incinerados. Su transformación en mariposa equivale a la creencia de un cambio de estado tras la incineración. Finalmente las costumbres migratorias de las mariposas Monarca, sería crucial para comprender la formación de una creencia del Centro de México en el que las almas de los difuntos regresan en distintos intervalos de tiempo. Según Nielsen (2018:93-95) las mariposas teotihuacanas constituyen pues, un símbolo de la representación de las almas de los muertos.

Por las escasas evidencias que presenta el complejo mariposa en el análisis de las figuras huéspedes, representado en apenas tres ejemplares, solamente puede sugerirse una asociación conectada tal vez al culto a la deidad o a representantes de la deidad. Tal y como ya señaló E. Pasztory (Berrin \& Pasztory 1993:210) son escasos los ejemplares en los que las figuras huéspedes definen rasgos de divinidad.

En esta propuesta inicial que presentamos aquí hemos tratado de definir los tipos, establecer sus variantes y evidenciar algunos rasgos compartidos por las figurillas huésped. El análisis de un posible código cromático que nos ayude al acercamiento en la identificación de dichas figurillas debe ser analizado, sin duda, con mayor profundidad. Asimismo puesto que las figurillas de arcilla mantienen cierta resistencia al cambio, la posibilidad de tratar de establecer conexiones o paralelos con otras figurillas de sitios más tardíos puede ayudar en esta tarea. Finalmente el breve análisis iconográfico presentado aquí acerca de la presencia de algunos elementos

22. Para Von Winning (1987:T.I, 168) la insignia “escudo con mano/flechas/lechuza” forma parte de la simbología mortuoria de Teotihuacan.

23. J.C. Berlo (1983) subrayó la vinculación de la mariposa con un carácter militarista. Sugiere la existencia de una diosa marcial mariposa teotihuacana, precursora de la diosa Xochiquetzal del período posclásico. También Headrick (2007:129-130) le concede atribuciones guerreras.

24. No olvidemos que su temprana relación con el agua había sido señalada y compartida por varios autores (Armillas 1945, Caso 1966, Kubler 1967) aunque no se descarta asimismo que estos insectos tengan relación con el inframundo y la residencia de las almas (Kubler, 1967:9). Esta última idea será secundada por varios autores, tal y como subrayó Sugiyama (1988:16-17). Paulinyi (2014) sintetiza que las lecturas iconográficas que han dominado son que se trata de la imagen del dios mariposa y de los guerreros, de ambos o de los representantes mortales del dios mariposa (Paulinyi 1995). 
simbólicos recurrentes detectados en los atributos de las huéspedes, como la flor de cuatro pétalos y la mariposa, parecería apuntar en estos casos a un contexto acuático, de fertilidad que frecuentemente se asocia también al Inframundo.

Esperamos en breve (artículo en preparación) poder apuntar algunos datos acerca de la problemática con los contextos, las cronologías y así como revisar y discutir las interpretaciones que se han forjado alrededor de su enigmática existencia.

\section{Bibliografía}

BALL, J.,1974. A Teotihuacán-Style Cache from the Maya Lowlands. Archaeology 27, 1: 2-9.

BARBOUR, W., 1976. The Figurines and figurine chronology of the Ancient Teotihuacan, Mexico. Tesis doctoral. University Microfilms International (UMI), Michigan.

BARBOUR, W., 1986. An analysis of Teotihuacan-type host figurines. 51 ${ }^{\text {st }}$ Annual Meeting. Program and abstracts. 2427 April. New Orleans, L.A. Society for American Archaeology, Washington, Ethnology Monographs, University of Pittsburg, pp.54-55.

BARBOUR, W. 1993. Host Figurines. En Teotihuacan: Art from the City of the Gods. K. Berrin, E. Pasztory (Eds.), pp.210.

BLISS, R.W., 1947. Indigenous Art of the Americas. Collection of Robert Wood Bliss. National Gallery of Art, Washington.

BONNAFOUX, P., LATSANOPOULOS, N., PATROIS, J., ARNAULD, M-C., MICHELET, D., NONDÉNÉO, P., PEREIRA, G., 2011. L'Un dans l'Autre: figurines Gigognes du Dépôt Spécial 69-2 de Becan, Mexique. En Profils d'objets. Approches d'anthropologues et archéologues. F. Wateau (Ed.), pp.6777. Colloques de la Maison René-Ginouvès, 7.

BERRIN, K., PASZTORY, E. (Eds.)., 1993. Teotihuacan. Art from the City of the Gods. Fine Arts Museum of San Francisco, Thames and Hudson, New York.

CONIDES, C., 2017. Figures in action: contextualizing the Butterfly Personage at Teotihuacan. En Visual Culture of the Ancient Americas: Contemporary Perspectives. A. Finegold, Blen Hoobler (Eds.), pp.103-118. Oklahoma Press, Norman.

CONIDES, C., 2018. Made to Order. Painted ceramics of Ancient Teotihuacan. Oklahoma Press, Norman.

COWGILL, G.L., 2008. Herencia de arcilla. Artes de México, 88: Cerámica de Teotihuacan: 16-29. México.

COWGILL, G. L., 2015. Ancient Teotihuacan. Early Urbanism in Central Mexico. Cambridge University Press, Cambridge.

DE LA FUENTE, B., 1993. Expression of the human figure in Pre-Hispanic art. En Human body. Human spirit. A portrait of ancient Mexico, F. Solís Olguín (Ed.), pp. 24-30. University of Pennsylvania, Philadelphia.

DUPEY, E., 2006. “Ulli, Tlilpopotzalli, Apetzli. Un acercamiento a las pinturas negras aztecas", en III Jornadas
Internacionales de Textiles Precolombinos, Victòria Solanilla (ed.), Barcelona, Grup d'Estudis Precolombins, Dept. D’Art, UAB: 71-86.

2009 "Xopan y Tonalco, los colores de las estacio-

nes entre los antiguos nahuas", en Aires y Lluvias. Antropología del clima en México, Annamária. Lammel, Marina Golaubinoff; Esther Kratz (eds.), CEMCA, CIESAS: 53-90.

2015 "The Materiality of color in the Body ornamentation of Aztec Gods", RES: Anthropology and Aesthetics 65-66: 672-88.

FAUGÈRE, B., 2014. Montrer ou cacher le corps humain. Quelques réflexions sur la conception du corps et ses représentations dans les hautes terres du Mexique préhispanique au Préclassique et au Classique. Ateliers d'anthropologie 40. Consulta on line URL: https://journals.openedition. org/ateliers/9622

GAZZOLA, J., GÓMEZ CHÁVEZ, S., CALLIGARO, Th. 2016. Identification and use of Pyrite and Hematite at Teotihuacan. En Manufactured light: mirrors in the Measomaerican realm. E.Gallaga, M.G. Blainey (Eds.), pp.107-214. University of Colorado Press, Boulder, Colorado.

GOLDSMITH, K.C, 2000. Forgotten Images: A Study of the Ceramic Figurines from Teotihuacan, Mexico. Tesis doctoral. UMI, Michigan.

HEADRICK, A., 2007. The Teotihuacan Trinity. The Sociopolitcal Structure of an Ancient Mesoamerican City. University of Texas Press, Austin.

HEADRICK, A., 1999. The Street of Dead...it really was: mortuary bundles at Teotihuacan. Ancient Mesoamerica 10: 69-85.

HELLMUTH, N. M., 1975. The Escuintla Hoards. Teotihuacan Art in Guatemala. F.L.A.A.R. Progress Reports, vol. 1, n.2.

HENDERSON, L., 2011. El poder del paisaje: Nuevas perspectivas sobre la presencia teotihuacana en las Tierras Altas y Costa Sur de Guatemala. B. Arroyo, L. Paiz, A. Linares y A. Arroyave (Eds.), pp. 584-596. Museo Nacional de Arqueología y Etnología, Guatemala (versión digital).

HEYDEN, D., 1977. "Economia y religion de Teotihuacan", en Cuadernos de Trabajo:19, México, INAH, Departamento de Etnología y Antropología Social: 1-48.

LÓPEZ AUSTIN, A., 1980. Cuerpo humano e ideología. Las concepciones de los antiguos nahuas. Vol.I. Universidad Nacional Autónoma de México, México.

NIELSEN, J., HELMKE, C., 2018. Where the sun came into being. Rites of Pyrolatry, Transition, and Transformation in Early Classic Teotihuacan. En Smoke, Flames and the Human Body in Mesoamerican Ritual Practice. V. Tiesler, A.K. Scherer (Eds.), pp. 77-107. Dumbarton Oaks Research, Washington.

NOGUERA, E. 1975. La cerámica arqueológica de Mesoamerica. Instituto Investigaciones Antropológicas, México.

MARCUS, J., Rethinking Figurines. En Mesoamerican Figurines. Small-scale Indices od Large-Scale Social Phenomena. C.T. Halperin, K. A. Faust, R. Taube, A. Giguet (Eds.), 
pp.25-50. University Press of Florida, Miami.

MILLER, M.E. 2012., The Art of Mesoamerica. From Olmec to Aztec. Thames \& Hudson. Col. World of Art. Londres.

MILLER, M., TAUBE, K., 1993 [1997]. An illustrated dictionary of The Gods and Symbols of Ancient Mexico and the Maya. Thames and Hudson, Londres.

MÚNERA, C. 1991., Una representación de bulto mortuorio. En Teotihuacan 1980-1982. nuevas interpretaciones. R.Cabrera Castro, I. Rodriguez García et al. (Eds.), pp.335341. Instituto Nacional de Antropología e Historia, Serie Arqueología, Col. Científica, México.

PASZTORY, E., 1997. Teotihuacan. An experiment in living. Oklahoma University Press, Norman.

PAULINYI, Z. 2014., The Butterfly bird god and his myth at Teotihuacan. Ancient Mesoamerica: 25 (1): 29-48.

ROBB, M., 2018. Teotihuacan: City of Water, City of Fire. Fine Arts Museum of San Francisco, de Young, University of California Press.

RODRÍGUEZ-SHADOW, M.J., 1997. Xochiquetzal: significado y simbolismo de una deidad prehispánica. En Homenaje a la doctora Beatriz Barba de Piña Chan. A. García Díaz, V. Becerril Olivares, M.C. Lechuga García, F. Rivas Castro (Eds.), pp. 425-432. INAH, Colección Científica 343, México.

SCOTT, S., 2001., The Terracotta Figurines from Sigvald Linné's Excavations at Teotihuacan, Mexico. Monograph Series 18, The National Museum of Ethnography, Stockholm.

SEJOURNÉ, L. 1966. El lenguaje de las formas en Teotihuacán, México. Litoarte, México.

SERRA PUCHE, M.C. 1998. Xochitécatl. Gobierno del Estado de Tlaxcala, México.

SERRA PUCHE, M.C., LAZCANO ARCE, J. C., 1997. XochitécatlCacaxtla en el periodo Epiclásico (650-950d.C). Arqueología, Revista de la Coordinación Nacional de Arqueología de México, 18 :85-102.

SOLÍS OLGUÍN, F., 1993. Human body. Human Spirit. A portrait of Ancient Mexico. Michael C.Carlos Museum, Emory University. Pennsylvania University Press, Philadelphia.

SPRANZ, B., 1973. Late Classic Figurines from Tlaxcala, Mexico and their possible relation to the Codex Borgia Group. En Mesoamerican Writing Systems, a Conference at Dumbarton Oaks, October $30^{\text {th }}-31^{\text {st }}, 1971$, E.P. Benson (Ed.), pp.217-225. Dumbarton Oaks Research Library and Collection, Washington.

SUGIYAMA, S. 2002. Censer symbolism and the state polity in Teotihuacán. FAMSI reports. http://www.famsi.org/report s/97050/97050Sugiyama01Text.pdf

SULLIVAN, K., 2007. Haciendo y manipulando el ritual en la Ciudad de los Dioses: producción y uso de figurillas en Teotihuacán, México. FAMSI reports. http://www.famsi. org/reports/03021es/

TATE, C. E., 1993. The human body and the realm of spirit. En: Human body. Human spirit. A portrait of ancient Mexico, F. Solís Olguín (Ed.), pp. 13-19. University of Pennsylvania, Philadelphia.
TESTARD, J., SERRA PUCHE, M.C., 2011. Las figurillas epiclásicas de la Pirámide de las Flores de Xochitécatl, Tlaxcala, México: tipología y simbolismo. Itinerarios, Revista de Estudios lingüísticos, literarios, históricos y antropológicos 14: 213-250.

TREJO, S., 2007. Xochiquétzal y Tlazotléotl. Diosas mexicas del amor y la sexualidad. Arqueología mexicana, 87, 18-25.

TREJO, S., 2000 [2004]. Dioses, Mitos y Ritos del México Antiguo. Miguel Ángel Porrúa, ed. México.

URIARTE, M.T. 1994. Teotihuacan: el legado de la ciudad de los dioses. En México en el Mundo de las Colecciones de Arte. Mesoamerica 1, M.L. Sabau García (Ed.). pp. 71-129, México.

VAILLANT, G.C. 1938. A correlation of archaeological and historial sequences in the Valley of Mexico. American Anthropologist, New Series, vol.40 (I):535-573.

VILLALONGA, A., 2015. Cuerpos de piedra en la Ciudad de los Dioses. Idiosincrasia de la escultura antropomorfa teotihuacana. Tesis doctoral. Universidad Autónoma de Barcelona, Bellaterra.

VON WINNING, H., 1987. La iconografía de Teotihuacán. Los dioses y los signos. 2 vols. Instituto de Investigaciones Estéticas, Col. Estudios y fuentes del arte en México, 47, UNAM, México.

VON WINNING, H., 1958. Figurines with movable limbs from Ancient Mexico. Ethnos 23 (1). Ethnographical Museum of Sweden, Stockholm.

WIDMER, R. W., 1987. The evolution of form and function in a Teotihuacan apartment compound: the case of Tlajinga 33. En: Teotihuacán: Nuevos datos, nuevas síntesis, nuevos problemas, E. Mc Clung de Tapia y E.C. Rattray (Eds.), pp. 317-368. Universidad Nacional Autónoma de México, México D.F.

VVAA. 2009. Teotihuacan. Cité des Dieux. Somogy éditions d'art, Musée du quai Branly, París.

VVAA. 2011. Teotihuacan. Ciudad de los Dioses. Catálogo. Obra Social La Caixa. INAH. México.

George Clapp Vaillant C.V en:

https://www.amnh.org/research/anthropology/collections/collections-history/meso-american-archaeology/ george-clapp-vaillant

https://www.amnh.org/research/anthropology/curatorial-research/meso-american-archaeology/projects/2.-san-francisco-mazapan/ george-clapp-vaillant-cv 